Article

\title{
Quantifying the Lost Safety Benefits of ADAS Technologies Due to Inadequate Supporting Road Infrastructure
}

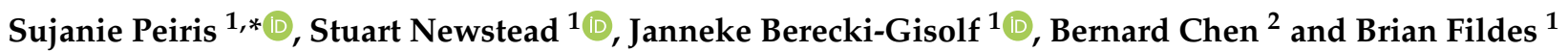 \\ 1 Accident Research Centre, Monash University, 21 Alliance Ln, Clayton, VIC 3800, Australia; \\ stuart.newstead@monash.edu (S.N.); janneke.berecki-gisolf@monash.edu (J.B.-G.); \\ brian.fildes@monash.edu (B.F.) \\ 2 Department of Mechanical and Aerospace Engineering, Monash University, 17 College Walk, \\ Clayton, VIC 3800, Australia; bernard.chen@monash.edu \\ * Correspondence: sujanie.peiris@monash.edu; Tel.: +61-3-9905-9979
}

check for

updates

Citation: Peiris, S.; Newstead, S.;

Berecki-Gisolf, J.; Chen, B.; Fildes, B. Quantifying the Lost Safety Benefits of ADAS Technologies Due to Inadequate Supporting Road Infrastructure. Sustainability 2022, 14, 2234. https://doi.org/10.3390/ su14042234

Academic Editors: Pablo García Triviño and Armando Cartenì

Received: 6 January 2022

Accepted: 14 February 2022

Published: 16 February 2022

Publisher's Note: MDPI stays neutral with regard to jurisdictional claims in published maps and institutional affiliations.

Copyright: (c) 2022 by the authors Licensee MDPI, Basel, Switzerland. This article is an open access article distributed under the terms and conditions of the Creative Commons Attribution (CC BY) license (https:// creativecommons.org/licenses/by/ $4.0 /)$.

\begin{abstract}
Advanced driver assistance systems (ADAS) provide warnings to drivers and, if applicable, intervene to mitigate a collision if one is imminent. Autonomous emergency brakes (AEB) and lane keep assistance (LKA) systems are mandated in several new vehicles, given their predicted injury and fatality reduction benefits. These predicted benefits are based on the assumption that roads are always entirely supportive of ADAS technologies. Little research, however, has been conducted regarding the preparedness of the road network to support these technologies in Australia, given its vastly expansive terrain and varying road quality. The objective of this study was to estimate what proportion of crashes that are sensitive to AEB and LKA, would not be mitigated due to unsupportive road infrastructure, and therefore, the lost benefits of the technologies due to inadequate road infrastructure. To do this, previously identified technology effectiveness estimates and a published methodology for identifying ADAS-supportive infrastructure availability was applied to an estimated AEB and LKA-sensitive crash subset (using crash data from Victoria, South Australia and Queensland, 2013-2018 inclusive). Findings demonstrate that while the road networks across the three states appeared largely supportive of AEB technology, the lack of delineation across arterial and sub-arterial (or equivalent) roads is likely to have serious implications on road safety, given $13-23 \%$ of all fatal and serious injury (FSI) crashes that occurred on these road classes were LKA-sensitive. Based on historical crash data, over 37 fatalities and 357 serious injuries may not be avoided annually across the three Australian states based on the lack of satisfactory road delineation on arterial and sub-arterial (or equivalent) roads alone. Further, almost $24 \%$ of fatalities in Victoria, $24 \%$ of fatalities in Queensland and 21\% of fatalities in South Australia (that are AEB- or LKA-sensitive) are unlikely to be prevented, given existing road infrastructure. These figures are conservative estimates of the lost benefits of the technologies as they only consider fatal and serious injury crashes and do not include minor injury or property damage crashes, the benefits of pedestrian-sensitive AEB crashes in high-speed zones or AEB fitted to heavy vehicles. It is timely for road investments to be considered, prioritised and allocated, given the anticipated penetration of the new technologies into the fleet, to ensure that the road infrastructure is capable of supporting the upcoming fleet safety improvements.
\end{abstract}

Keywords: infrastructure; LKA; AEB; ADAS; road-readiness

\section{Introduction}

Vehicle technology is seen as a great potential for improving road safety globally and in Australia, given that driver error is thought to be a contributing factor in over $94 \%$ of crashes [1,2]. Consequently, numerous studies have estimated and reported the benefits of advanced driver assist technologies [2-23]. Independent of the methods employed by researchers to obtain effectiveness estimates of vehicle technologies, all studies assume that the road conditions on which the technologies will perform are consistently ideal. 
Yet, little is known about the ability of the existing road network to support these vehicle technologies. While previous research has demonstrated that not all roads are optimised for supporting advanced in-vehicle technologies [24], no study, to date, has quantified what proportion of technology-sensitive crashes are unlikely to be prevented due to the technologies failing as a result of poor road infrastructure. A study is needed to quantify how much of the assumed benefits of advanced driver assistance systems (ADAS) that have been derived in previous studies will not be realised because of suboptimal roads and driving conditions.

ADAS are a class of in-vehicle technologies that help minimise driver error by providing drivers with timely warnings, potentially intervening to mitigate a collision if one is imminent. Such technologies are also precursor to autonomous vehicles [25] and are regarded highly by the automotive industry. These technologies, including lane keep assistance (LKA), intelligent speed adaptation (ISA), blind spot detection (BSD) and autonomous emergency braking (AEB) are predicted to bring about significant road safety gains in terms of crash reduction, and consequently, fatality and serious injury reductions to all road users [26-30]. In recognition of this, vehicle testing authorities are encouraging the inclusion of ADAS technologies as standard, with higher star ratings being issued for vehicles that have specific technologies fitted [31]. It is expected that ADAS technologies will perform optimally in all driving conditions, enhancing a driver's ability to remain in control of their vehicle, or in the event of an unavoidable crash, minimise crash severity. ADAS technologies, however, are reliant on vehicle-fitted sensors collecting and interpreting the correct information from the driving and road environment in order to function properly [32-34]. Without adequate supportive information, the ability of the technology to function and its effectiveness are likely to be compromised.

Specifically, ADAS technologies, such as AEB and LKA, are touted as being technologies that are likely to reduce road trauma both globally [4,8,9,35,36], and in Australia [30,37-39]. AEB has the ability to detect potential frontal impacts (either with cars or pedestrians, depending on the type of AEB), warn the driver and/or engage automatic vehicle braking if a crash appears imminent. The functionality of AEB is dependent on the type of AEB system fitted into vehicles, which can differ between manufacturers. Camera based systems and those fitted with short-range radars are typically only effective in city driving conditions (typically operational up to speeds of $60 \mathrm{~km} / \mathrm{h}$ ) and are referred to as urban-AEB systems), while AEB systems that are equipped with combination cameras and long-range radars can function at higher speeds $(60-210 \mathrm{~km} / \mathrm{h}$, referred to as interurban AEB systems) [40]. The effectiveness of these systems is highly dependent on the combinations of the cameras and radars used, and the sensitivity of these sensors within the systems. LKA technologies detect a vehicle's deviation from the intended lane of travel and alert the driver, applying corrective steering and/or differential braking to prevent lane departure if no action is taken by the driver, reducing crash risk $[5,7,18]$. Typically, LKA is operational being between $65-200 \mathrm{~km} / \mathrm{h}$, depending on the vehicle manufacture [18,41]. Together, the technologies are predicted to reduce the incidence of rear-end impacts [8] and certain head-on impacts [6,30,42,43], as well as loss of control or run-off-road impacts $[18,21,38]$.

In acknowledgement of the lifesaving benefits of these technologies, the fitment of AEB and lane keep assist technologies, amongst other ADAS technologies, will be made mandatory in new European vehicles from 2022 onward [44]. Australia has followed suit, with the Australian government mandating AEB technology from 2023, so that all new vehicles manufactured from 2025 have the technology [45]. Industry support for an equivalent ADR (107/00) that will see the installation of LKA systems in all new light vehicles and sets performance requirements to maximise the safety benefits of the technology is currently being sought [46]. It is noteworthy, however, that while both AEB and LKA have the capacity to eliminate or at least mitigate the severity of rear-end impacts, pedestrian impacts and run-off-road crashes, they are highly dependent on supportive road infrastructure [47-49]. For example, AEB is unlikely to be effective on gravel or unsealed 
roads and lane keep assist technologies are unlikely to function at all on roads that have poor or no delineation. Therefore, the ability of these technologies to perform optimally will most likely be compromised in locations where supportive road infrastructure is absent.

Roads in regional and remote Australia, in particular, are likely to be problematic given that anecdotally, upkeep of these roads is funded more sparingly than urban roads [50-54] so they are less likely to meet the requirements for ADAS. Yet, these roads allow for high travel speeds and are responsible for a disproportionate amount of road trauma [55]. Research that quantifies the predicted benefits of AEB and LKA often fail to acknowledge assumptions made about roads on which cars fitted with these technologies will be driven $[16,17,20,21]$. Studies that estimate the lifesaving benefits of these technologies, which are based on how they have already performed, fail to take into account the forgone benefits of the technologies due to absent infrastructure. While this is partly due to the fact that it is difficult to estimate technology performance on poorly equipped roads, it is also due to the lack of available data on supportive road infrastructure. Whilst for experimental purposes, vehicles fitted with ADAS technologies are currently being driven on various roads and terrains, these studies are not cost effective for obtaining data about vehicle performance and technology effectiveness in different driving environments [47,49]. Such experimental studies are time- and labour-intensive and the data they provide are limited by where the vehicle is driven or under what conditions. A more reasonable means of determining where these technologies are likely to fail and the consequences of this in terms of lost benefits is needed, so that the effectiveness of technologies such as AEB and LKA are not over-estimated and road infrastructure funding can be allocated based on need.

Studies that have previously estimated the benefits of advanced driver assist technologies have been conducted on the basis that road conditions are always adequate to support the technologies. The assumption that the entire road network is fully supportive of systems such as AEB, LKA and ISA, however, is severely flawed [24]. The objective of this study was to quantify what proportion of the crash population that is assumed to be mitigated by AEB and LKA, will not actually be mitigated due to absent road infrastructure. By quantifying the number of fatalities and serious injuries that are unlikely to be prevented by the technologies due to the inability of the technologies to function (as a result of unsupportive road infrastructure), the lost benefits of AEB and LKA technologies will be estimated. When the foregone benefits of ADAS technologies have been identified, appropriate investments can then be made to ensure that the technologies consistently perform as intended and provide life-saving benefits to all road users.

\section{Materials and Methods}

This study consisted of three main components:

1. Determining the real-world appropriateness of AEB and LKA using a previously published methodology to identify availability of adequate road infrastructure as gauged by bitumen quality (as a predictor of AEB performance) and presence of road delineation (as a predictor of LKA performance) in three states (Victoria, Queensland and South Australia), across road class and remoteness levels.

2. Identifying AEB and LKA-sensitive fatal and serious injury (FSI) crashes (and the number of people killed and injured as a result of these crashes) in these jurisdictions, across varying road classes and remoteness levels based on 6 years of historical crash data (2013-2018). For the purposes of this investigation, 'fatal' refers to the death of an occupant within 30 days of the crash and 'serious injury' is defined as where hospital admission was required following the crash.

3. Applying the relative crash risk reduction estimates related to AEB-sensitive and LKAsensitive crashes identified by Newstead et al., 2020 [30] and Newstead et al., 2021 [38] to the AEB and LKA-sensitive crash subsets identified in (2), taking into account road bitumen quality and road delineation quality identified in (1), to establish the number of fatalities and serious injuries that are likely/unlikely to be prevented by the technologies, across road classes and remoteness levels in the three states. 


\subsection{Identifying the Availability of Adequate Road Infrastructure}

The previously identified methodology [24] was used to determine the availability of high-, medium- and low-quality bitumen as well as the availability of high-, medium-, adequate- and low-quality delineation across road classes across the three states. In brief, this involved identifying the distribution of FSI crashes across the road networks disaggregated by remoteness levels (as defined by the ABS 2016 [56]). A number of random locations were used for sampling, stratifying the sampling by road class (and remoteness level), based on the distribution of FSI crashes. Existing remoteness categories including "Major Cities", "Regional Australia" (representing both Inner Regional Australia and Outer Regional Australia) and "Remote Australia" (representing both Remote Australia and Very Remote Australia) were assigned, as per the ARIA Index [57]. Crash data (2013-2018 inclusive) from the three states were used for this purpose. Crash location data was obtained from respective state authorities to determine where (using GPS coordinates) each crash occurred.

The desktop analysis used ArcGIS satellite imagery to determine how each road class ranked within each remoteness level in terms of bitumen quality and delineation availability. Bitumen quality and delineation availability was ranked according to the previously published protocol [24]. In brief, this involved ranking bitumen quality as high, medium or low, and delineation quality as high, medium, adequate or low as per the definitions and examples presented in Supplementary Table S1 [24].

The distribution of FSI across road classes and remoteness levels and the resulting sampling framework for each state are presented in Supplementary Tables S4-S7. The quality of bitumen and delineation for each state (by road class and remoteness level) are presented in Supplementary Tables S8-S19. It is noteworthy that since the road networks in each state are managed at the state level, road classes between states can differ markedly and, thus, the results for each state have been presented separately. In Victoria for example, freeways, highways and arterial roads typically provide the principal routes for the movement of people and goods between major regions and population centres, while local and collector roads provide access for general traffic (from major freeways to minor local roads or from minor roads to tracks in parks). Since roads in each state are declared according to respective Government Gazettes and Road Management Acts [58-61], broad definitions across the road classes were used in study to ensure consistent road categories were used across the states.

Road quality and delineation data for each of the three states were collected by one individual to maintain internal consistency in the assessments, but subsequently verified by a separate, independent assessor. Interrater reliability or measure of agreement for road surface quality and delineation quality was measured using the kappa statistic $(k)$ after $20 \%$ of the data were re-analysed for each state. The interrater reliability results are presented in Supplementary Table S2. In summary, for road bitumen quality assessments, the interrater reliability assessment indicate moderate to substantial levels of agreement between raters [62]. The kappa statistic for road delineation quality across states indicated moderate to strong level of agreement between raters [62].

\subsection{Identifying AEB Sensitive Crash Types}

The methods employed by Newstead, Budd and Stephens [30] were used to identify ADAS-sensitive FSI crashes from the crash data in Victoria, Queensland and South Australia to determine the proportion of crashes that are likely to be sensitive to AEB technology. Crashes sensitive to AEB were defined as being narrowly sensitive, broadly sensitive and pedestrian sensitive as summarised below. The specifics related to how the striking and struck vehicle were defined for each AEB-sensitive crash type for the purposes of this analysis are presented in Supplementary Table S79.

Narrowly sensitive crashes are those crashes that are likely to be strongly sensitive to AEB; these are predominately rear-end impacts $[6,8,9]$. Though these represent a narrow range of collision types, the technology is considered to be highly effective in these crashes. 
Broadly sensitive crashes are those considered to be sensitive to forward collisions such as head-on impacts where AEB, if fitted, is likely to intervene and enhance braking. These are a broader range of crash scenarios where AEB is likely to function, albeit with less certainty when compared with narrowly sensitive crashes. Identified by Anderson, Hutchinson, Linke and Ponte [43], these were intersection crashes, head-on or overtaking crashes and U-turn crashes. The struck vehicle in these crashes could be either a light or heavy vehicle. Motor vehicle collisions with bicycles, pedestrians, and other non-fixed objects were excluded from this analysis.

Pedestrian sensitive crashes are those likely to be mitigated by pedestrian-AEB systems. These are crashes that occur between a vehicle and a vulnerable road user (VRU, i.e., pedestrian or bicyclist) when the VRU either crosses the path of an on-road vehicle or when a VRU is travelling on-road in the same/opposite direction as the vehicle. In this crash subset, the impact between the vehicle and pedestrian or bicycle had to be the primary impact (i.e., not secondary to an impact), and the vehicle had to be moving.

Narrowly sensitive crashes were further dichotomised based on whether the primary (impacting) vehicle was a light motor vehicle ("AEB Narrow-Light Vehicle") or a heavy motor vehicle ("AEB Narrow-Heavy Vehicle"). Research has demonstrated that AEB fitted to heavy vehicles (unlike light vehicles) is unlikely to mitigate impacts with vulnerable road users (i.e., pedestrians, cyclists), or to mitigate impact types that AEB, fitted to light vehicles, is typically broadly sensitive to, such as intersection crashes [63]. For these reasons, heavy vehicles (defined as those with a gross vehicle mass, GVM, greater than 4.5 tons) were defined as having only narrow AEB sensitivity. That is, AEB fitted to heavy vehicles was considered to only be sensitive to crash types such as rear-end impacts, which are generally very likely to be mitigated by AEB technology $[64,65]$.

The DCA (Definitions for Classifying Accidents) codes associated with FSI crashes in the crash data [66] were used to identify the subset of narrowly, broadly and pedestriansensitive crashes (Supplementary Tables S78 and S79). DCA codes are typically assigned by the police officer attending a crash and provide information regarding accident type, road geometry, road characteristics, traffic control and the role of the vehicles in the impact (Supplementary Figures S1 and S2). The DCAs reflective of narrowly sensitive, broadly sensitive and pedestrian-sensitive light vehicle crashes and narrowly sensitive heavy vehicle crashes are outlined in Supplementary Tables S78 and S79.

Given the functional differences between city-AEB and inter-urban AEB systems [40], for the purposes of analysis, the AEB systems were differentiated using a speed limit of $60 \mathrm{~km} / \mathrm{h}$ (i.e., $\leq 60 \mathrm{~km} / \mathrm{h}$ vs. $>60 \mathrm{~km} / \mathrm{h}$ ).

\subsection{Identifying LKA-Sensitive Crash Types}

Crashes sensitive to LKA were defined only as being LKA-sensitive (no further categories), as defined by Newstead and researchers [38]. These were single vehicle and multivehicle crashes that resulted from unintentional lane departures (including head-on impacts and sideswipe impacts), which occurred at speeds of $70 \mathrm{~km} / \mathrm{h}$ or greater. Since LKA technologies can typically only function at above 60 or $70 \mathrm{~km} / \mathrm{h}$ (depending on vehicle manufacture) [41], the 'speed zone' variable in the crash data was used for identifying crashes that occurred at speeds of above $70 \mathrm{~km} / \mathrm{h}$. Crashes that resulted from intentional lane changes such as changing lanes, merging, turning or reversing prior to the impact were excluded from the analysis. Since line markings and the associated road environment, and hence the potential benefits of LKA, differ between built up and open road environments that can broadly be differentiated by speed limits $(<100 \mathrm{~km} / \mathrm{h}$ and $\geq 100 \mathrm{~km} / \mathrm{h})$ the LKA analysis was dichotomized by speed limit, also consistent with the analysis conducted by Newstead et al., [38].

Only light vehicles were subject to the LKA analysis, with all other vehicles (including heavy vehicles, non-vehicles, non-motorised vehicles, and motorcycles) excluded from the analysis. LKA-sensitive crashes were selected based DCA codes (Supplementary Table S78) and number of specific criteria (Supplementary Table S79), as specified in [38]. 


\subsection{Identifying AEB and LKA Effectiveness Values}

Technology effectiveness estimates can be identified using various sources. Large naturalistic driving studies involving AEB- or LKA-equipped vehicles that would typically provide the most accurate effectiveness rates are yet to be conducted [3], so, for estimating the effectiveness of these technologies, other methods are usually employed.

An extensive literature review was conducted to identify subsets of crashes that have been considered sensitive to AEB or LKA, the methods employed by other authors to estimate technology effectiveness (often defined as crash mitigation or injury reduction potential) or AEB and LKA technology effectiveness estimates published by other researchers. It was anticipated that findings from previous research, particularly related to technology effectiveness values, could be used in this study. Studies that were published between 2014-2021, conducted in Europe, North America or Australasia and used data based on (at least in part) real-world crashes were included in a literature review so that the findings could be applied to an Australian context. Studies published using data from Asian countries were excluded, given the crash configurations and speeds would be too dissimilar to those that occur in Australia. For identifying AEB-sensitive crashes and AEB effectiveness values, studies by the following researchers, were considered: Edwards, Nathanson and Wisch (2014) [67]; Rizzi et al. (2014) [9]; Fildes et al. (2015) [8]; Isaksson-Hellman and Lindman (2016) [42]; Cicchino (2017) [6]; Ohlin, Strandroth and Tingvall (2017) [68]; Sander (2017) [69]; Silla et al. (2017) [70]; Jeppsson, Östling and Lubbe (2018) [14]; Sander and Lubbe (2018) [4]; Spicer et al. (2018) [2]; Chajmowicz, Saadé and Cuny (2019) [12]; Sander, Lubbe and Pietzsch (2019) [71]; Seacrist et al. (2019) [3] and Newstead et al. (2020) [30]. For identifying LKA-sensitive crashes and LKA effectiveness values, studies by the following researchers were considered: Kusano et al. (2014) [20]; Scanlon et al., (2015) [17]; Sternlund et al. (2017) [21]; Cicchino (2018) [5]; Isaksson-Hellman and Lindman (2018) [7] and Penmetsa et al. (2019) [18].

AEB-sensitive crash subsets and effectiveness values identified by Newstead, Budd and Stephens [30], and the LKA-sensitive crash subsets and effectiveness value identified by Newstead, Watson and Budd [38] were used in this analysis. 'AEB effectiveness' was defined by these authors as a percentage reduction in Australian police reported target crashes and associated injuries associated with AEB fitment in crashes involving light or heavy vehicles, while 'LKA effectiveness' was defined as the percentage reduction in Australian police reported target crashes and the resulting injuries associated with LKA fitment in crashes involving light vehicles. For both AEB and LKA, the effectiveness estimates for light vehicles were obtained by the authors using police reported crash data from Australia, using induced exposure methods and by fitting Poisson regression models to the light vehicle-sensitive crash data, based on previous induced exposure crash risk studies [8,9]. This method induces travel exposure for a vehicle based on its involvement in a particular crash type, overcoming the inability to measure crash risk directly. In doing so, the authors present relative risk (RR) estimates, which identify the relative risk of an AEB- or LKA-fitted vehicle being involved in a crash potentially mitigated by AEB or LKA technology, compared with a vehicle not fitted with the respective technology. The relevant RR values that were used in this study are presented in Supplementary Table S3. As an example, a RR of 0.72 for a fatal or serious injury for an AEB-fitted light vehicle involved in a narrowly sensitive crash, implies a $28 \%((1.0-0.72) \times 100 \%)$ reduction in fatal or serious injury risk. The reader is referred to the original studies by Newstead and researchers $[30,38]$ for a detailed explanation regarding how AEB and LKA effectiveness values (respectively) were derived.

It is noteworthy that the effectiveness of AEB in heavy vehicles identified in the above studies [30] was based on empirical literature since the relevant data required to obtain a direct estimation of crash reductions associated with AEB fitment using Australian heavy vehicle crash data was not possible. Heavy vehicle AEB effectiveness estimates identified by Woodrooffe, et al. [72] including AEB effectiveness based on currently available AEB technology (lower bounds) and the predicted AEB effectiveness based on future generations 
of AEB technology (upper bounds), were adopted by Newstead, Budd and Stephens [30] and also used here.

\subsection{Estimations of the Distributions of Fatal and SI ADAS-Sensensitive Crashes}

The proportion of FSI crashes across Victoria, Queensland and South Australia, over the six-year period and the number of fatalities and serious injuries that result annually (based on the historical crash data) from ADAS-sensitive crashes across road networks (disaggregated by remoteness) are presented in the supplementary tables. The number of technology-sensitive fatalities and serious injuries that are likely to be avoided or unavoided based on road class and remoteness level are also presented as supplementary tables separately for each state, disaggregated by technology type and speed zone. The following is a brief description regarding the distribution of these crashes in each state.

\subsection{Fatal and SI Crashes That Are Sensitive to AEB and LKA}

The proportion of FSI crashes across Victoria, Queensland and South Australia, over the six-year period being studied and expressed in terms of annual average, are presented in Supplementary Table S20. While Victoria and Queensland have similar numbers of fatally and seriously injured people from FSI crashes, the annual figures in South Australia are approximately 3.5 and 6.5 times less for fatalities and serious injuries, respectively, compared with Victoria. This is possibly reflective of the population and vehicle ownership rates, with the population of Victoria and Queensland being almost four times and three times larger (respectively) than South Australia's resident population, while vehicle ownership is three-and-a-half times and three times greater in Victoria and Queensland compared with South Australia [73]. Supplementary Tables S21-S23 present the number of individuals who were killed or seriously injured (in each state) in crash types that were considered to be sensitive to specific AEB and LKA technologies, however a summary table is presented here (Table 1 ).

Table 1. The proportion of AEB- and LKA-sensitive crashes in Victoria (Vic), South Australia (SA) and Queensland (QLD), and the number of individuals fatally (F) or seriously injured (SI) in the sensitive crash subsets.

\begin{tabular}{|c|c|c|c|c|c|c|c|c|c|}
\hline \multirow{3}{*}{ State } & \multirow{3}{*}{$\begin{array}{l}\text { Total FSI } \\
\text { Crashes }\end{array}$} & \multicolumn{4}{|c|}{$\%$ Technology-Sensitive Crashes } & \multicolumn{4}{|c|}{ Individuals in Sensitive Crashes } \\
\hline & & \multicolumn{3}{|c|}{ AEB } & \multirow{2}{*}{ LKA } & \multicolumn{2}{|c|}{ AEB } & \multicolumn{2}{|c|}{ LKA } \\
\hline & & Narrow & Broad & Ped'n & & $\mathbf{F}$ & SI & $\mathbf{F}$ & SI \\
\hline Vic & 24,697 & 10.5 & 25.7 & 9.4 & 16.8 & 653 & 13,097 & 555 & 4580 \\
\hline SA & 3116 & 4.5 & 17.0 & 0.4 & 23.4 & 147 & 1356 & 168 & 1026 \\
\hline QLD & 32,603 & 12.5 & 26.7 & 2.4 & 13.7 & 510 & 17,965 & 476 & 5573 \\
\hline
\end{tabular}

In Victoria, of the 1396 fatal crashes and 23,301 serious injury crashes that occurred over the 6-year period, approximately $11 \%, 26 \%$ and $9 \%$ of crashes were narrowly, broadly and pedestrian-sensitive (respectively) to AEB technologies. Almost $17 \%$ of crashes were sensitive to LKA. In total, 653 individuals were killed and 13,097 seriously injured in AEB-sensitive crash types over the six-year period, while 555 and 4580 people were killed and seriously injured respectively, in LKA-sensitive crashes. The results were similar in Queensland, over the 6-year period with $12 \%, 26 \%$ and $2 \%$ of crashes being sensitive to narrow, broad and pedestrian-AEB technologies. Although the magnitude of FSI crashes in South Australia was lower compared with Victoria and Queensland, the number of people killed and seriously injured in AEB-and LKA-sensitive crash types was proportionately comparable to the two larger states. That is, of the 415 fatal crashes and 2701 serious injury crashes that occurred in South Australia over the same 6-year period, $4.5 \%, 17 \%$ of crashes were sensitive to narrow and broad AEB technologies; however, over $23 \%$ were sensitive to 
LKA technology. Across the three states, LKA-sensitive crash types were responsible for a disproportionate number of deaths and serious injuries.

\subsection{Calculating the Lost Benefits of $A E B$ and $L K A$}

The lost benefits of the technologies were estimated by identifying the number of individuals who would be killed or seriously injured in crashes that should have been mitigated by AEB or LKA (assuming the vehicles were fitted with the appropriate technology), but where the road infrastructure prevented the technology from functioning. The following equations (Equations (1) and (2)) were used to estimate the lost benefits of AEB and LKA, where RR refers to relative risk.

Lost Benefits of $A E B$

$=($ Proportion of total crash population targetted by $A E B \times(1-R R$ of $A E B))$

$\times$ Proportion of road network unsupportive of $A E B$

Lost Benefits of $L K A=($ Proportion of total crash population targetted by $L K A \times(1-R R$ of $L K A)) \times$ Proportion of road network unsupportive of LKA

\section{Results}

There are an extensive number of tables due to the results being technology-, speedand state-specific. These detailed results have been presented as an online Supplement for the sake of brevity. A flow chart is presented within each results section providing a schematic overview of how the results have been derived and are presented within the Supplement, with table numbers identifying where specific results can be found.

\subsection{ADAS-Sensitive Crashes on Roads with ADAS Compatible Infrastructure}

Figure 1 (Supplementary Tables S20-S50) highlight the number of fatalities and serious injuries annually that result from ADAS-sensitive crashes across road networks (disaggregated by remoteness level) in each state (based on historical crash data).

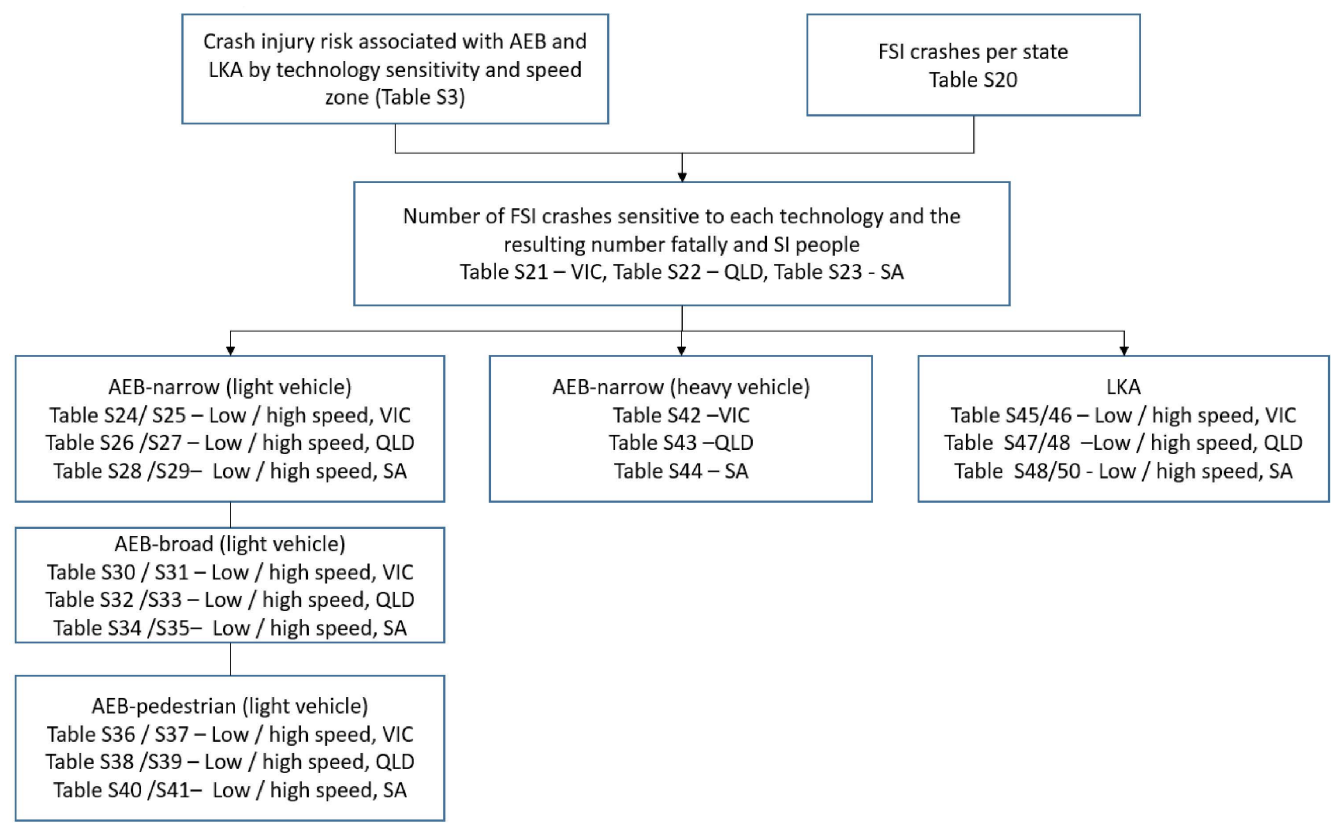

Figure 1. Flow chart of the result tables (in the Supplement) that contain estimates of the number of FSI crashes sensitive to each technology type.

Since the performance/effectiveness of AEB systems can vary based on the travel speed of the vehicle $[6,9,42,63]$, the AEB effectiveness analysis for light vehicles was conducted for low-speed zones $(\leq 60 \mathrm{~km} / \mathrm{h})$ and high-speed zones $(>60 \mathrm{~km} / \mathrm{h})$, using the 
speed zone variable identified in the crash data. AEB fitted to heavy vehicles are tested at $80 \mathrm{~km} / \mathrm{h}$ (as per UNR131 regulation, UN 2013) with the intension that AEB assists with high-speed heavy vehicle impacts. As there was no data regarding AEB effectiveness in heavy vehicles in any particular speed zone, all speeds were included in the estimated benefits of AEB in heavy vehicles by Newstead et al., [30] for the subset of heavy vehicle crashes, with the same done here.

Taking into account the proportion of roads that have high-, medium- and low-quality bitumen (Figure 2, Supplementary Tables S4-S19), and assuming that these (respectively) represent where the technology is most likely, reasonably likely and unlikely to perform, the number of fatalities and serious injuries likely avoided could be compared with those likely not to be avoided due to poor road infrastructure. In calculating the potential benefits of AEB and LKA, it was assumed that the technology will be fitted to all vehicles and, therefore, in the event that the vehicle is exposed to a sensitive crash type, its ability to mitigate the crash will be dependent on the available/supportive road infrastructure (in this case, high-quality bitumen).

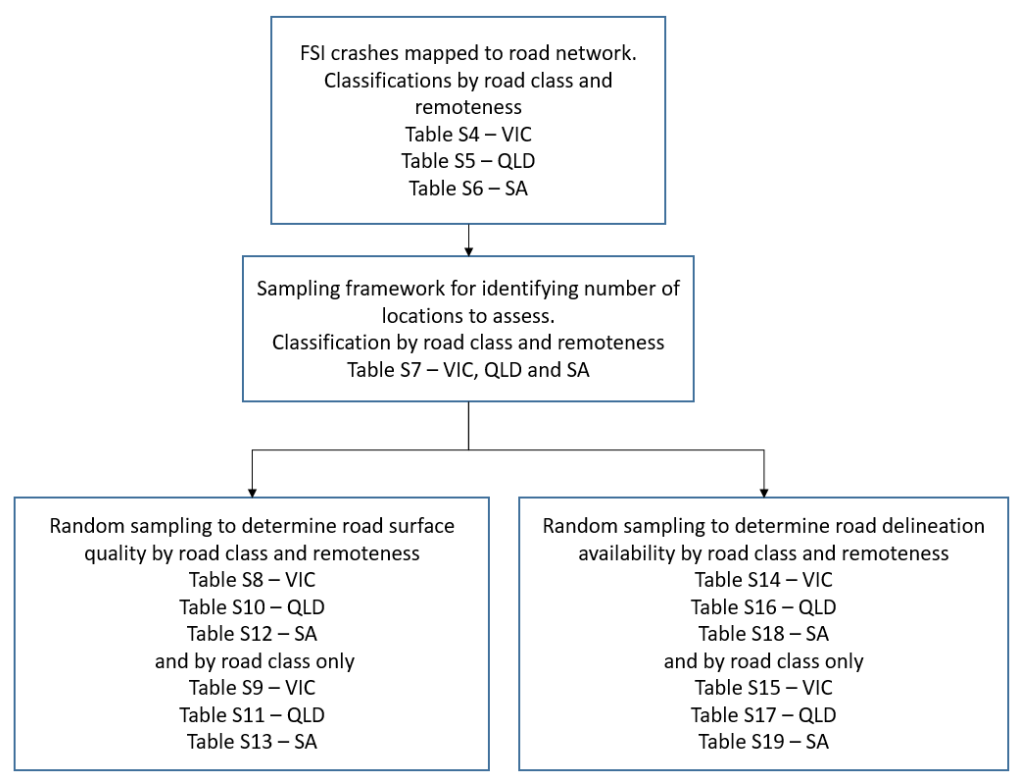

Figure 2. Result tables (in the Supplement) that contain estimated proportions of roads with high-, medium- and low-quality bitumen and road delineation for each state, by road class and remoteness level and by road class only (derived using [24]).

The number of technology-sensitive fatalities and serious injuries that are likely to avoided and unavoided based on road class and remoteness level are presented separately for each state, disaggregated by technology type and speed zone (Figure 3, Supplementary Tables S51-S77).

\subsection{Fatalities and Serious Injuries Unlikely to Be Avoided in ADAS-Sensitive Crashes Based on Unsuitable Road Infrastructure}

Estimates of the fatalities and serious injuries that are likely to continue to occur annually (assuming all vehicles are fitted with AEB and LKA technologies) are presented in this section. These estimates have been derived using the previously published methodology (Peiris et al., [24]) to identify the availability of adequate road infrastructure, proxied using bitumen quality (as a predictor of AEB performance) and presence of road delineation (as a predictor of LKA performance) across Victoria, Queensland and South Australia (Figure 2). The number of AEB- and LKA-sensitive FSI crashes (and the number of people killed and injured as a result of these crashes) over 6 years of historical crash data (2013-2018) were then estimated (Figure 1). By applying the relative crash risk reduction estimates related to AEB-sensitive and LKA-sensitive crashes identified by Newstead et al., [30] and 
Newstead et al., [38] to the AEB- and LKA-sensitive crash subsets and taking into account road bitumen quality and road delineation quality, the number of fatalities and serious injuries that are likely/unlikely to be prevented by the technologies across road classes and remoteness levels in the three states were estimated (Figure 3). Extracted from this data, Tables 2-4 present estimates of the fatalities and serious injuries that are likely to continue to occur annually (once all vehicles are fitted with AEB and LKA technologies).

\begin{tabular}{|c|c|c|c|c|c|}
\hline \multirow{2}{*}{ Technology } & \multirow{2}{*}{ Sensitivity } & \multirow{2}{*}{$\begin{array}{c}\text { Speed zone } \\
(\mathrm{km} / \mathrm{h})\end{array}$} & \multicolumn{3}{|c|}{ Table No. } \\
\hline & & & VIC & QLD & SA \\
\hline \multirow{6}{*}{$\begin{array}{c}\text { AEB - light } \\
\text { vehicle }\end{array}$} & \multirow{2}{*}{ Narrow } & $<60$ & S51 & S60 & S69 \\
\hline & & $\geq 60$ & S52 & S61 & $\mathrm{S} 70$ \\
\hline & \multirow{2}{*}{ Broad } & $<60$ & S53 & S62 & $\mathrm{S} 71$ \\
\hline & & $\geq 60$ & S54 & S63 & $\mathrm{S} 72$ \\
\hline & \multirow{2}{*}{ Pedestrian } & $<60$ & S55 & S64 & $\mathrm{S} 73$ \\
\hline & & $\geq 60$ & S56 & S65 & S74 \\
\hline $\begin{array}{c}\text { AEB - heavy } \\
\text { vehicle }\end{array}$ & Narrow & All & S57 & S66 & S75 \\
\hline \multirow{2}{*}{ LKA } & \multirow{2}{*}{ NA } & $<100$ & S58 & S67 & $\mathrm{S} 76$ \\
\hline & & $\geq 100$ & S59 & S68 & $\mathrm{S} 77$ \\
\hline
\end{tabular}

Figure 3. Supplementary tables with estimates of fatalities and serious injuries that are likely to be (un)avoided in each state based on technology-sensitive crash types.

In Victoria, the lost benefits of AEB technologies are likely to be greatest on councilmaintained local roads, where over 16 serious injuries annually are likely to continue to occur due to poor bitumen quality or lack of bitumen. The performance of the technology in narrowly sensitive, broadly sensitive and pedestrian-sensitive AEB crashes that occur in low-speed zones in particular, are likely to be compromised. LKA-technology is unlikely to perform optimally on arterial and sub-arterial roads, with almost one fatality and over 16 serious injuries predicted to continue to occur annually in speed-zones less than 100 $\mathrm{km} / \mathrm{h}$ and over 3 fatalities and 26 serious injuries likely to continue to occur in LKAsensitive crashes on high-speed zones due to suboptimal or absent delineation. Not surprisingly AEB is likely to perform most reliably on freeways and highways in Victoria, with the bitumen quality analysis (see Supplementary tables) showing that almost all of these road types (across remoteness levels) are sealed with high quality bitumen. While the delineation quality across a number of highways was questionable, the greatest losses from LKA technologies (in terms of fatalities and serious injuries) are likely to be due to poor delineation on arterial and sub-arterial road networks in Victoria.

In Queensland, AEB technology (across all three sensitivities) are likely to underperform on secondary roads, connector roads, and streets, with 6,9 and 31 serious injuries likely to continue to occur annually on these road types, respectively, due to poor bitumen quality or presence of unsealed roads. Narrowly sensitive crashes and broadly sensitive crashes in low-speed zones in particular, are likely to be responsible for over 31 serious injuries on these road classes. Based on Queensland-specific historical crash data, fatalities that result in AEB-sensitive crashes are likely to be avoided on freeways and highways due to bitumen quality being high on these roads. Unlike AEB-sensitive crash types, a greater number of fatalities and serious injuries are likely to continue to occur in LKA-sensitive crashes that occur on secondary roads and connector roads assuming all such roads are signed at $70 \mathrm{~km} / \mathrm{h}$ or greater, where LKA is expected to function. In speed zones of less than $100 \mathrm{~km} / \mathrm{h}$, it is estimated that over 22 fatalities and 187 serious injuries are likely to continue to occur annually on secondary and connector roads, while in speed zones equal to or greater than $100 \mathrm{~km} / \mathrm{h}$, based on historical data and lane delineation quality, less than 2 fatalities but over 12 serious injuries are likely to continue to occur annually. Highways signed at less than $100 \mathrm{~km} / \mathrm{h}$ are also likely to be responsible for over 2 fatalities and close to 14 serious injuries annually. 
Table 2. Annual fatalities (F) and serious injuries (SI) unlikely to be avoided in vehicles fitted with AEB and LKA, due to inadequate infrastructure. Results for Victoria; shown by road class and speed zone.

\begin{tabular}{|c|c|c|c|c|c|c|c|c|c|c|c|c|c|c|c|c|c|c|}
\hline \multirow{4}{*}{$\begin{array}{l}\text { Road } \\
\text { Type }\end{array}$} & \multicolumn{12}{|c|}{ AEB, Light Vehicle } & \multirow{3}{*}{\multicolumn{2}{|c|}{$\begin{array}{c}\begin{array}{c}\text { AEB, Heavy } \\
\text { Vehicle }\end{array} \\
\text { Narrow } \\
\text { All }\end{array}$}} & \multirow{2}{*}{\multicolumn{4}{|c|}{$\begin{array}{c}\text { LKA } \\
\text { NA } \\
\end{array}$}} \\
\hline & \multicolumn{4}{|c|}{ Narrow } & \multicolumn{4}{|c|}{ Broad } & \multicolumn{4}{|c|}{ Pedestrian } & & & & & & \\
\hline & \multicolumn{2}{|c|}{$\begin{array}{c}\leq 60 \mathrm{~km} / \mathrm{h} \\
p=0.09\end{array}$} & \multicolumn{2}{|c|}{$\begin{array}{c}>60 \mathrm{~km} / \mathrm{h} \\
p=0.008\end{array}$} & \multicolumn{2}{|c|}{$\begin{array}{c}\leq 60 \mathrm{~km} / \mathrm{h} \\
p=0.30\end{array}$} & \multicolumn{2}{|c|}{$\begin{array}{c}>60 \mathrm{~km} / \mathrm{h} \\
p=0.42\end{array}$} & \multicolumn{2}{|c|}{$\begin{array}{c}\leq 60 \mathrm{~km} / \mathrm{h} \\
p=0.62\end{array}$} & \multicolumn{2}{|c|}{$\begin{array}{c}>60 \mathrm{~km} / \mathrm{h} \\
p=0.70\end{array}$} & & & \multicolumn{2}{|c|}{$\begin{array}{c}<100 \mathrm{~km} / \mathrm{h} \\
p=0.004\end{array}$} & \multicolumn{2}{|c|}{$\begin{array}{c}\geq 100 \mathrm{~km} / \mathrm{h} \\
p=0.004\end{array}$} \\
\hline & $\mathbf{F}$ & SI & $\mathbf{F}$ & SI & $\mathbf{F}$ & SI & $\mathbf{F}$ & SI & $\mathbf{F}$ & SI & $\mathbf{F}$ & SI & $\mathbf{F}$ & SI & $\mathbf{F}$ & SI & $\mathbf{F}$ & SI \\
\hline freeways & $\begin{array}{c}0.00 \\
(0.00 \\
0.00)\end{array}$ & $\begin{array}{c}0.00 \\
(-0.01 \\
0.01)\end{array}$ & $\begin{array}{c}0.00 \\
(-0.03 \\
0.03)\end{array}$ & $\begin{array}{c}0.00 \\
(-0.03 \\
0.03)\end{array}$ & $\begin{array}{c}0.00 \\
(0.00 \\
0.00)\end{array}$ & $\begin{array}{c}0.00 \\
(0.00 \\
0.00)\end{array}$ & $\begin{array}{c}0.00 \\
(0.00 \\
0.00)\end{array}$ & $\begin{array}{c}0.00 \\
(0.00 \\
0.00)\end{array}$ & $\begin{array}{c}0.00 \\
(-0.02 \\
0.02)\end{array}$ & $\begin{array}{c}0.00 \\
(-0.02 \\
0.02)\end{array}$ & $\begin{array}{c}0.00 \\
(0.00 \\
0.01)\end{array}$ & $\begin{array}{l}0.00 \\
(0.00 \\
0.00)\end{array}$ & 0 & 0 & $\begin{array}{c}0.01 \\
(0.01 \\
0.02)\end{array}$ & $\begin{array}{c}0.21 \\
(0.20 \\
0.21)\end{array}$ & $\begin{array}{l}0.06 \\
(0.06, \\
0.07)\end{array}$ & $\begin{array}{l}0.88 \\
(0.87 \\
0.89)\end{array}$ \\
\hline highway & $\begin{array}{c}0.00 \\
(0.00 \\
0.00)\end{array}$ & $\begin{array}{c}0.00 \\
(-0.01 \\
0.01)\end{array}$ & $\begin{array}{c}0.00 \\
(-0.03 \\
0.03)\end{array}$ & $\begin{array}{c}0.00 \\
(-0.03 \\
0.03)\end{array}$ & $\begin{array}{l}0.00 \\
(0.00 \\
0.00)\end{array}$ & $\begin{array}{c}0.00 \\
(0.00 \\
0.00)\end{array}$ & $\begin{array}{l}0.00 \\
(0.00 \\
0.00)\end{array}$ & $\begin{array}{l}0.00 \\
(0.00 \\
0.00)\end{array}$ & $\begin{array}{c}0.00 \\
(-0.02 \\
0.02)\end{array}$ & $\begin{array}{c}0.00 \\
(0.02, \\
0.02)\end{array}$ & $\begin{array}{c}0.00 \\
(0.00 \\
0.01)\end{array}$ & $\begin{array}{l}0.00 \\
(0.00 \\
0.00)\end{array}$ & 0 & 0 & $\begin{array}{l}0.25 \\
(0.25 \\
0.26)\end{array}$ & $\begin{array}{l}3.43 \\
(3.42, \\
3.44)\end{array}$ & $\begin{array}{c}0.28 \\
(0.28 \\
0.29)\end{array}$ & $\begin{array}{c}1.78 \\
(1.78 \\
1.79)\end{array}$ \\
\hline arterial & $\begin{array}{c}0.00 \\
(0.00 \\
0.00)\end{array}$ & $\begin{array}{c}0.02 \\
(0.01 \\
0.03)\end{array}$ & $\begin{array}{c}0.01 \\
(-0.02 \\
0.04)\end{array}$ & $\begin{array}{c}0.11 \\
(0.08 \\
0.14)\end{array}$ & $\begin{array}{c}0.00 \\
(0.00 \\
0.00)\end{array}$ & $\begin{array}{c}0.05 \\
(0.05 \\
0.05)\end{array}$ & $\begin{array}{l}0.03 \\
(0.03 \\
0.03)\end{array}$ & $\begin{array}{c}0.21 \\
(0.21 \\
0.21)\end{array}$ & $\begin{array}{c}0.00 \\
(-0.02 \\
0.02)\end{array}$ & $\begin{array}{c}0.03 \\
(0.01 \\
0.05)\end{array}$ & $\begin{array}{c}0.00 \\
(0.00 \\
0.01)\end{array}$ & $\begin{array}{c}0.00 \\
(-0.01 \\
0.00)\end{array}$ & 0 & $0-0.04$ & $\begin{array}{l}0.54 \\
(0.53 \\
0.55)\end{array}$ & $\begin{array}{l}9.29 \\
(9.29 \\
9.30)\end{array}$ & $\begin{array}{l}1.87 \\
(1.86 \\
1.87)\end{array}$ & $\begin{array}{l}10.22 \\
(10.21, \\
10.23)\end{array}$ \\
\hline subarterial & $\begin{array}{c}0.01 \\
(-0.13 \\
0.15)\end{array}$ & $\begin{array}{l}1.03 \\
(1.01 \\
1.04)\end{array}$ & $\begin{array}{c}0.06 \\
(0.03 \\
0.09) \\
\end{array}$ & $\begin{array}{l}1.95 \\
(1.91 \\
1.98) \\
\end{array}$ & $\begin{array}{c}0.04 \\
(0.03 \\
0.04) \\
\end{array}$ & $\begin{array}{l}1.43 \\
(1.43 \\
1.43) \\
\end{array}$ & $\begin{array}{c}0.40 \\
(0.39 \\
0.40)\end{array}$ & $\begin{array}{c}4.32 \\
(4.31 \\
4.33) \\
\end{array}$ & $\begin{array}{c}0.08 \\
(0.05 \\
0.10) \\
\end{array}$ & $\begin{array}{c}0.73 \\
(0.70 \\
0.75) \\
\end{array}$ & $\begin{array}{l}-0.09 \\
(-0.09 \\
-0.08)\end{array}$ & $\begin{array}{c}-0.08 \\
(-0.17 \\
0.01)\end{array}$ & 0 & $0-0.01$ & $\begin{array}{c}0.39 \\
(0.38 \\
0.39) \\
\end{array}$ & $\begin{array}{l}7.38 \\
(7.38 \\
7.39) \\
\end{array}$ & $\begin{array}{c}1.97 \\
(1.97 \\
1.98) \\
\end{array}$ & $\begin{array}{l}16.10 \\
(16.09, \\
16.11)\end{array}$ \\
\hline collector & $\begin{array}{c}0.00 \\
(-0.14 \\
0.14)\end{array}$ & $\begin{array}{c}0.59 \\
(0.58, \\
0.60)\end{array}$ & $\begin{array}{c}0.00 \\
(-0.04 \\
0.04)\end{array}$ & $\begin{array}{l}0.50 \\
(0.46, \\
0.54)\end{array}$ & $\begin{array}{c}0.05 \\
(0.05, \\
0.05)\end{array}$ & $\begin{array}{l}1.01 \\
(1.01, \\
1.01)\end{array}$ & $\begin{array}{l}0.02 \\
(0.01, \\
0.02)\end{array}$ & $\begin{array}{l}0.62 \\
(0.61, \\
0.63)\end{array}$ & $\begin{array}{l}0.05 \\
(0.01 \\
0.10)\end{array}$ & $\begin{array}{l}0.89 \\
(0.84 \\
0.93)\end{array}$ & $\begin{array}{l}-0.06 \\
(-0.07 \\
-0.05)\end{array}$ & $\begin{array}{c}-0.02 \\
(-0.08 \\
0.05)\end{array}$ & 0 & 0 & NA & NA & NA & NA \\
\hline local & $\begin{array}{c}0.04 \\
(-0.10 \\
0.18)\end{array}$ & $\begin{array}{l}2.85 \\
(2.84 \\
2.86)\end{array}$ & $\begin{array}{c}0.06 \\
(0.02 \\
0.09)\end{array}$ & $\begin{array}{l}1.93 \\
(1.89 \\
1.96)\end{array}$ & $\begin{array}{c}0.11 \\
(0.10 \\
0.11)\end{array}$ & $\begin{array}{c}4.61 \\
(4.61 \\
4.61)\end{array}$ & $\begin{array}{c}0.38 \\
(0.38 \\
0.38)\end{array}$ & $\begin{array}{l}3.21 \\
(3.20 \\
3.22)\end{array}$ & $\begin{array}{c}0.22 \\
(0.18 \\
0.25)\end{array}$ & $\begin{array}{l}3.50 \\
(3.46 \\
3.54)\end{array}$ & $\begin{array}{l}-0.30 \\
(-0.30 \\
-0.29)\end{array}$ & $\begin{array}{c}-0.15 \\
(-0.45 \\
0.15)\end{array}$ & 0 & $0-0.2$ & NA & NA & NA & NA \\
\hline
\end{tabular}


Table 3. Fatalities (F) and serious injuries (SI) unlikely to be avoided in vehicles fitted with AEB and LKA, due to inadequate infrastructure. Results for Queensland; shown by road class and speed zone.

\begin{tabular}{|c|c|c|c|c|c|c|c|c|c|c|c|c|c|c|c|c|c|c|}
\hline \multirow{4}{*}{$\begin{array}{l}\text { Road } \\
\text { Type }\end{array}$} & \multicolumn{12}{|c|}{ AEB, Light Vehicle } & \multirow{3}{*}{\multicolumn{2}{|c|}{$\begin{array}{c}\text { AEB, Heavy Vehicle } \\
\text { Narrow } \\
\text { All }\end{array}$}} & \multirow{2}{*}{\multicolumn{4}{|c|}{$\begin{array}{c}\text { LKA } \\
\text { NA }\end{array}$}} \\
\hline & \multicolumn{4}{|c|}{ Narrow } & \multicolumn{4}{|c|}{ Broad } & \multicolumn{4}{|c|}{ Pedestrian } & & & & & & \\
\hline & \multicolumn{2}{|c|}{$\begin{array}{c}\leq 60 \mathrm{~km} / \mathrm{h} \\
p=0.09\end{array}$} & \multicolumn{2}{|c|}{$\begin{array}{c}>60 \mathrm{~km} / \mathrm{h} \\
p=0.008\end{array}$} & \multicolumn{2}{|c|}{$\begin{array}{c}\leq 60 \mathrm{~km} / \mathrm{h} \\
p=0.30\end{array}$} & \multicolumn{2}{|c|}{$\begin{array}{c}>60 \mathrm{~km} / \mathrm{h} \\
p=0.42\end{array}$} & \multicolumn{2}{|c|}{$\begin{array}{c}\leq 60 \mathrm{~km} / \mathrm{h} \\
p=0.62\end{array}$} & \multicolumn{2}{|c|}{$\begin{array}{c}>60 \mathrm{~km} / \mathrm{h} \\
p=0.70\end{array}$} & & & \multicolumn{2}{|c|}{$\begin{array}{c}<100 \mathrm{~km} / \mathrm{h} \\
p=0.004\end{array}$} & \multicolumn{2}{|c|}{$\begin{array}{c}\geq 100 \mathrm{~km} / \mathrm{h} \\
p=0.004\end{array}$} \\
\hline & $\mathbf{F}$ & SI & $\mathbf{F}$ & SI & $\mathbf{F}$ & SI & $\mathbf{F}$ & SI & $\mathbf{F}$ & SI & $\mathbf{F}$ & SI & $\mathbf{F}$ & SI & $\mathbf{F}$ & SI & $\mathbf{F}$ & SI \\
\hline freeway & $\begin{array}{c}0.00 \\
(-0.01 \\
0.01)\end{array}$ & $\begin{array}{c}0.00 \\
(-0.01 \\
0.01)\end{array}$ & $\begin{array}{c}0.00 \\
(-0.01 \\
0.01)\end{array}$ & $\begin{array}{c}0.00 \\
(-0.01 \\
0.01)\end{array}$ & $\begin{array}{l}0.00 \\
(0.00 \\
0.00)\end{array}$ & $\begin{array}{c}0.00 \\
(0.00 \\
0.00)\end{array}$ & $\begin{array}{c}0.00 \\
(0.00 \\
0.00) \\
\end{array}$ & $\begin{array}{c}0.00 \\
(0.00 \\
0.00)\end{array}$ & $\begin{array}{c}0.00 \\
(-0.02 \\
0.02)\end{array}$ & $\begin{array}{c}0.00 \\
(-0.02 \\
0.02)\end{array}$ & $\begin{array}{c}0.00 \\
(-0.02 \\
0.02)\end{array}$ & $\begin{array}{c}0.00 \\
(-0.02 \\
0.02)\end{array}$ & 0 & 0 & $\begin{array}{c}0.19 \\
(0.19 \\
0.20)\end{array}$ & $\begin{array}{r}6.25 \\
(6.25 \\
6.26) \\
\end{array}$ & $\begin{array}{c}0.05 \\
(0.04 \\
0.05)\end{array}$ & $\begin{array}{c}0.00 \\
(-0.01, \\
0.01)\end{array}$ \\
\hline highway & $\begin{array}{c}0.00 \\
(-0.01 \\
0.01)\end{array}$ & $\begin{array}{c}0.00 \\
(-0.01 \\
0.01)\end{array}$ & $\begin{array}{c}0.00 \\
(-0.01 \\
0.01)\end{array}$ & $\begin{array}{c}0.00 \\
(-0.01 \\
0.01)\end{array}$ & $\begin{array}{c}0.00 \\
(0.00 \\
0.00)\end{array}$ & $\begin{array}{c}0.00 \\
(0.00 \\
0.00)\end{array}$ & $\begin{array}{c}0.00 \\
(0.00 \\
0.00)\end{array}$ & $\begin{array}{l}0.00 \\
(0.00 \\
0.00)\end{array}$ & $\begin{array}{c}0.00 \\
(-0.02, \\
0.02)\end{array}$ & $\begin{array}{c}0.00 \\
(-0.02 \\
0.02)\end{array}$ & $\begin{array}{c}0.00 \\
(-0.02 \\
0.02)\end{array}$ & $\begin{array}{c}0.00 \\
(-0.02 \\
0.02)\end{array}$ & 0 & 0 & $\begin{array}{l}2.23 \\
(2.22 \\
2.23)\end{array}$ & $\begin{array}{l}13.87 \\
(13.87 \\
13.88)\end{array}$ & $\begin{array}{l}0.25 \\
(0.25 \\
0.26)\end{array}$ & $\begin{array}{c}0.02 \\
(0.01 \\
0.02)\end{array}$ \\
\hline secondary & $\begin{array}{c}0.00 \\
(-0.01 \\
0.01)\end{array}$ & $\begin{array}{l}1.49 \\
(1.48 \\
1.50) \\
\end{array}$ & $\begin{array}{c}0.02 \\
(0.00 \\
0.03) \\
\end{array}$ & $\begin{array}{l}1.89 \\
(1.88 \\
1.90) \\
\end{array}$ & $\begin{array}{c}0.02 \\
(0.01 \\
0.02) \\
\end{array}$ & $\begin{array}{l}1.31 \\
(1.30 \\
1.31) \\
\end{array}$ & $\begin{array}{c}0.16 \\
(0.16 \\
0.16) \\
\end{array}$ & $\begin{array}{l}1.38 \\
(1.37 \\
1.38) \\
\end{array}$ & $\begin{array}{c}0.02 \\
(-0.01 \\
0.04)\end{array}$ & $\begin{array}{c}0.11 \\
(0.08, \\
0.13) \\
\end{array}$ & $\begin{array}{c}-0.01 \\
(-0.03 \\
0.02)\end{array}$ & $\begin{array}{c}-0.01 \\
(-0.04 \\
0.01)\end{array}$ & 0 & $0.1-0.4$ & $\begin{array}{l}15.44 \\
(15.43, \\
15.45)\end{array}$ & $\begin{array}{c}111.99 \\
(111.98, \\
112.00)\end{array}$ & $\begin{array}{c}0.40 \\
(0.40 \\
0.41) \\
\end{array}$ & $\begin{array}{l}2.64 \\
(2.63 \\
2.65) \\
\end{array}$ \\
\hline connector & $\begin{array}{c}0.00 \\
(-0.01 \\
0.02)\end{array}$ & $\begin{array}{l}2.92 \\
(2.91 \\
2.93)\end{array}$ & $\begin{array}{c}0.00 \\
(-0.01 \\
0.01)\end{array}$ & $\begin{array}{l}1.52 \\
(1.50 \\
1.53)\end{array}$ & $\begin{array}{c}0.03 \\
(0.03 \\
0.03)\end{array}$ & $\begin{array}{c}3.77 \\
(3.77 \\
3.77)\end{array}$ & $\begin{array}{c}0.09 \\
(0.09 \\
0.10)\end{array}$ & $\begin{array}{l}1.18 \\
(1.17 \\
1.18)\end{array}$ & $\begin{array}{c}0.02 \\
(-0.01 \\
0.06)\end{array}$ & $\begin{array}{c}0.44 \\
(0.41 \\
0.47)\end{array}$ & $\begin{array}{c}0.00 \\
(-0.03 \\
0.03)\end{array}$ & $\begin{array}{c}-0.01 \\
(-0.04 \\
0.03)\end{array}$ & $0.2-0.6$ & $0.17-0.38$ & $\begin{array}{c}6.91 \\
(6.90 \\
6.91)\end{array}$ & $\begin{array}{l}75.06 \\
(75.06 \\
75.07) \\
\end{array}$ & $\begin{array}{l}1.08 \\
(1.08 \\
1.09)\end{array}$ & $\begin{array}{l}10.24 \\
(10.24, \\
10.25)\end{array}$ \\
\hline streets & $\begin{array}{c}0.00 \\
(-0.01 \\
0.02)\end{array}$ & $\begin{array}{l}6.57 \\
(6.56 \\
6.58)\end{array}$ & $\begin{array}{c}0.07 \\
(0.06 \\
0.08)\end{array}$ & $\begin{array}{l}3.10 \\
(3.08, \\
3.11)\end{array}$ & $\begin{array}{l}0.12 \\
(0.12 \\
0.13)\end{array}$ & $\begin{array}{l}15.61 \\
(15.60, \\
15.61)\end{array}$ & $\begin{array}{l}0.21 \\
(0.20 \\
0.21)\end{array}$ & $\begin{array}{l}3.79 \\
(3.79, \\
3.79)\end{array}$ & $\begin{array}{c}0.17 \\
(0.13 \\
0.21)\end{array}$ & $\begin{array}{l}2.27 \\
(2.23 \\
2.30)\end{array}$ & $\begin{array}{c}-0.01 \\
(-0.04 \\
0.03)\end{array}$ & $\begin{array}{c}-0.03 \\
(-0.07 \\
0.01)\end{array}$ & $0.2-0.5$ & $0.13-1.81$ & NA & NA & NA & NA \\
\hline
\end{tabular}


Table 4. Fatalities (F) and serious injuries (SI) unlikely to be avoided in vehicles fitted with AEB and LKA, due to inadequate infrastructure. Results for South Australia; shown by road class and speed zone.

\begin{tabular}{|c|c|c|c|c|c|c|c|c|c|c|c|c|c|c|c|c|c|c|}
\hline \multirow{4}{*}{$\begin{array}{l}\text { Road } \\
\text { Type }\end{array}$} & \multicolumn{12}{|c|}{ AEB, Light Vehicle } & \multirow{3}{*}{\multicolumn{2}{|c|}{$\begin{array}{c}\begin{array}{c}\text { AEB, Heavy } \\
\text { Vehicle }\end{array} \\
\text { Narrow } \\
\text { All }\end{array}$}} & \multirow{2}{*}{\multicolumn{4}{|c|}{$\begin{array}{c}\text { LKA } \\
\text { NA }\end{array}$}} \\
\hline & \multicolumn{4}{|c|}{ Narrow } & \multicolumn{4}{|c|}{ Broad } & \multicolumn{4}{|c|}{ Pedestrian } & & & & & & \\
\hline & \multicolumn{2}{|c|}{$\begin{array}{c}\leq 60 \mathrm{~km} / \mathrm{h} \\
p=0.09\end{array}$} & \multicolumn{2}{|c|}{$\begin{array}{c}>60 \mathrm{~km} / \mathrm{h} \\
p=0.008\end{array}$} & \multicolumn{2}{|c|}{$\begin{array}{c}\leq 60 \mathrm{~km} / \mathrm{h} \\
p=0.30\end{array}$} & \multicolumn{2}{|c|}{$\begin{array}{c}>60 \mathrm{~km} / \mathrm{h} \\
p=0.42\end{array}$} & \multicolumn{2}{|c|}{$\begin{array}{c}\leq 60 \mathrm{~km} / \mathrm{h} \\
p=0.62\end{array}$} & \multicolumn{2}{|c|}{$\begin{array}{c}>60 \mathrm{~km} / \mathrm{h} \\
p=0.70\end{array}$} & & & \multicolumn{2}{|c|}{$\begin{array}{c}<100 \mathrm{~km} / \mathrm{h} \\
p=0.004\end{array}$} & \multicolumn{2}{|c|}{$\begin{array}{c}\geq 100 \mathrm{~km} / \mathrm{h} \\
p=0.004\end{array}$} \\
\hline & $\mathbf{F}$ & SI & $\mathbf{F}$ & SI & $\mathbf{F}$ & SI & $\mathbf{F}$ & SI & $\mathbf{F}$ & SI & $\mathbf{F}$ & SI & $\mathbf{F}$ & SI & $\mathbf{F}$ & SI & $\mathbf{F}$ & SI \\
\hline freeways & $\begin{array}{c}0.00 \\
(-0.01 \\
0.01)\end{array}$ & $\begin{array}{c}0.00 \\
(-0.01 \\
0.01)\end{array}$ & $\begin{array}{c}0.00 \\
(-0.04, \\
0.04)\end{array}$ & $\begin{array}{c}0.00 \\
(-0.04 \\
0.04)\end{array}$ & $\begin{array}{l}0.00 \\
(0.00 \\
0.00)\end{array}$ & $\begin{array}{c}0.00 \\
(0.00 \\
0.00)\end{array}$ & $\begin{array}{c}0.00 \\
(0.00 \\
0.00)\end{array}$ & $\begin{array}{l}0.00 \\
(0.00 \\
0.00)\end{array}$ & $\begin{array}{c}0.00 \\
(-0.02, \\
0.02)\end{array}$ & $\begin{array}{c}0.00 \\
(-0.02 \\
0.02)\end{array}$ & $\begin{array}{c}0.00 \\
(-0.01, \\
0.01)\end{array}$ & $\begin{array}{c}0.00 \\
(-0.01 \\
0.01)\end{array}$ & 0 & 0 & $\begin{array}{c}0.00 \\
(0.00 \\
0.00)\end{array}$ & $\begin{array}{c}0.00 \\
(0.00 \\
0.00)\end{array}$ & $\begin{array}{c}0.00 \\
(0.00 \\
0.00)\end{array}$ & $\begin{array}{c}0.00 \\
(0.00, \\
0.00)\end{array}$ \\
\hline highway & $\begin{array}{c}0.00 \\
(-0.01 \\
0.01)\end{array}$ & $\begin{array}{c}0.00 \\
(-0.01 \\
0.01)\end{array}$ & $\begin{array}{c}0.00 \\
(-0.04, \\
0.04)\end{array}$ & $\begin{array}{c}0.00 \\
(-0.04 \\
0.04)\end{array}$ & $\begin{array}{l}0.00 \\
(0.00 \\
0.00)\end{array}$ & $\begin{array}{c}0.00 \\
(0.00 \\
0.00)\end{array}$ & $\begin{array}{c}0.00 \\
(0.00 \\
0.00)\end{array}$ & $\begin{array}{l}0.00 \\
(0.00 \\
0.00)\end{array}$ & $\begin{array}{c}0.00 \\
(-0.02, \\
0.02)\end{array}$ & $\begin{array}{c}0.00 \\
(-0.02 \\
0.02)\end{array}$ & $\begin{array}{c}0.00 \\
(-0.01, \\
0.01)\end{array}$ & $\begin{array}{c}0.00 \\
(-0.01 \\
0.01)\end{array}$ & 0 & 0 & $\begin{array}{c}0.02 \\
(0.02, \\
0.03)\end{array}$ & $\begin{array}{c}0.10 \\
(0.10 \\
0.11)\end{array}$ & $\begin{array}{c}0.00 \\
(-0.01 \\
0.01)\end{array}$ & $\begin{array}{l}0.03 \\
(0.02, \\
0.03)\end{array}$ \\
\hline arterial & $\begin{array}{c}0.00 \\
(-0.01 \\
0.01)\end{array}$ & $\begin{array}{c}0.03 \\
(0.01 \\
0.04) \\
\end{array}$ & $\begin{array}{c}0.00 \\
(-0.04 \\
0.04)\end{array}$ & $\begin{array}{c}0.03 \\
(-0.01 \\
0.07)\end{array}$ & $\begin{array}{l}0.00 \\
(0.00 \\
0.00)\end{array}$ & $\begin{array}{c}0.01 \\
(0.00 \\
0.01)\end{array}$ & $\begin{array}{l}0.02 \\
(0.02, \\
0.02)\end{array}$ & $\begin{array}{c}0.11 \\
(0.11 \\
0.11) \\
\end{array}$ & $\begin{array}{c}0.00 \\
(-0.02, \\
0.02) \\
\end{array}$ & $\begin{array}{c}0.00 \\
(-0.02 \\
0.03)\end{array}$ & $\begin{array}{c}0.00 \\
(-0.01, \\
0.01)\end{array}$ & $\begin{array}{c}0.00 \\
(-0.01 \\
0.01)\end{array}$ & 0 & 0 & $\begin{array}{c}0.17 \\
(0.17 \\
0.18)\end{array}$ & $\begin{array}{c}0.52 \\
(0.52, \\
0.53)\end{array}$ & $\begin{array}{c}0.27 \\
(0.27 \\
0.28)\end{array}$ & $\begin{array}{c}1.30 \\
(1.30, \\
1.31) \\
\end{array}$ \\
\hline subarterial & $\begin{array}{c}0.00 \\
(-0.02 \\
0.02)\end{array}$ & $\begin{array}{c}0.01 \\
(0.00 \\
0.03)\end{array}$ & $\begin{array}{c}0.00 \\
(-0.04 \\
0.04)\end{array}$ & $\begin{array}{l}0.09 \\
(0.05 \\
0.13)\end{array}$ & $\begin{array}{l}0.00 \\
(0.00 \\
0.00)\end{array}$ & $\begin{array}{c}0.10 \\
(0.10 \\
0.10)\end{array}$ & $\begin{array}{c}0.01 \\
(0.01 \\
0.02)\end{array}$ & $\begin{array}{l}0.25 \\
(0.25 \\
0.25)\end{array}$ & $\begin{array}{c}0.00 \\
(-0.04, \\
0.04)\end{array}$ & $\begin{array}{c}0.01 \\
(-0.03 \\
0.04)\end{array}$ & $\begin{array}{c}0.00 \\
(-0.01, \\
0.01)\end{array}$ & $\begin{array}{c}0.00 \\
(-0.01 \\
0.01)\end{array}$ & 0 & 0 & $\begin{array}{l}1.03 \\
(1.02, \\
1.04)\end{array}$ & $\begin{array}{c}1.71 \\
(1.70, \\
1.71)\end{array}$ & $\begin{array}{c}0.48 \\
(0.47 \\
0.48)\end{array}$ & $\begin{array}{l}2.61 \\
(2.60, \\
2.61)\end{array}$ \\
\hline collector & $\begin{array}{c}0.00 \\
(-0.01, \\
0.02)\end{array}$ & $\begin{array}{c}0.04 \\
(0.02, \\
0.05)\end{array}$ & $\begin{array}{c}0.00 \\
(-0.04 \\
0.04)\end{array}$ & $\begin{array}{c}0.00 \\
(-0.04 \\
0.04)\end{array}$ & $\begin{array}{l}0.01 \\
(0.01 \\
0.02)\end{array}$ & $\begin{array}{c}0.09 \\
(0.08 \\
0.09)\end{array}$ & $\begin{array}{c}0.04 \\
(0.03, \\
0.04)\end{array}$ & $\begin{array}{l}0.36 \\
(0.36 \\
0.36)\end{array}$ & $\begin{array}{c}0.00 \\
(-0.02, \\
0.03)\end{array}$ & $\begin{array}{c}0.00 \\
(-0.02 \\
0.03)\end{array}$ & $\begin{array}{c}0.00 \\
(-0.01, \\
0.01)\end{array}$ & $\begin{array}{c}0.00 \\
(-0.01 \\
0.00)\end{array}$ & 0 & 0 & NA & NA & NA & NA \\
\hline local & $\begin{array}{c}0.00 \\
(-0.02 \\
0.02)\end{array}$ & $\begin{array}{l}0.42 \\
(0.40 \\
0.44)\end{array}$ & $\begin{array}{c}0.07 \\
(0.02 \\
0.12)\end{array}$ & $\begin{array}{l}0.66 \\
(0.61 \\
0.72)\end{array}$ & $\begin{array}{l}0.03 \\
(0.03 \\
0.04)\end{array}$ & $\begin{array}{c}0.59 \\
(0.59 \\
0.60)\end{array}$ & $\begin{array}{c}0.23 \\
(0.23 \\
0.24)\end{array}$ & $\begin{array}{l}1.90 \\
(1.90 \\
1.90)\end{array}$ & $\begin{array}{c}0.00 \\
(-0.07 \\
0.07)\end{array}$ & $\begin{array}{c}0.00 \\
(-0.07 \\
0.07)\end{array}$ & $\begin{array}{c}0.00 \\
(-0.01, \\
0.01)\end{array}$ & $\begin{array}{c}-0.03 \\
(-0.04 \\
-0.02)\end{array}$ & 0 & $0.1-0.3$ & NA & NA & NA & NA \\
\hline
\end{tabular}


As previously noted, due to the population and vehicle ownership rates being greater in the state of Victoria (and Queensland), the annual fatality and serious injury rates in South Australia are approximately 3.5 and 6.5 times less for fatalities and serious injuries respectively, compared with Victoria (see Supplementary Tables S4-S6), the proportion of fatalities and serious injuries that occur in ADAS-sensitive crash types on South Australia's road networks is therefore also comparatively less. Due to this and potentially the smaller and well-maintained road network that exists in South Australia, the lost benefits of AEB and LKA technologies are far less in South Australia compared with Victoria and Queensland. It was estimated that less than one fatality and three serious injuries are unlikely to be avoided (annually) in South Australia on local roads due to poor-quality bitumen. Based on the South Australian-specific crash trends, all road classes appeared supportive of AEB technologies both in low- and high-speed zones. LKA technologies are unlikely to prevent one fatality and just over two serious injuries in speed zones of less than $100 \mathrm{~km} / \mathrm{h}$ on arterial and sub arterial roads, while the technology is unlikely to prevent less than one fatality and close to three serious injuries in high-speed zones on the same road classes.

\subsection{Summary of Fatalities and Serious Injuries Avoided, Potentially Avoided and Unavoided}

Table 5 summarises the numbers of fatalities and serious injuries that are likely to be avoided, potentially avoided and unlikely to be avoided based on (a) the likely occurrence of AEB narrowly, broadly and pedestrian-sensitive crashes (using historical crash data as a predictor of crash trends), (b) based on bitumen quality (as a proxy of AEB functional likelihood) and (c) delineation availability (as a proxy of LKA functional likelihood). Since LKA had an extra category when estimating the fatalities and serious injuries prevented based on the ability of high-performing LKA systems to function on roads where no delineation was present but high-contrasting shoulders were visible (see Peiris et al., [24]), it was assumed for the purposes of the following summary, that these systems are unlikely to be highly prevalent in the vehicle fleet in the near future. As such, the fatalities and serious injuries that are likely to result on such roads were assumed not to be prevented by LKA systems. Therefore, the two categories identified as "Likely unavoided (Adequate delineation)" and "Unavoided (Low or no delineation)" have been collapsed into a single category, "Unavoided". Further, due to the effectiveness estimates of pedestrian AEB systems in high-speed environments being reported to be statistically not significant by Newstead et al., [30], the likely benefits of this technology in high-speeds zones has not been included in the summary table. Additionally, due to the low numbers of fatalities and serious injuries that resulted from heavy vehicle crashes over the historical crash period examined, the potential effects of the technologies on these crashes have not been included below. 
Table 5. Overall summary of fatalities (F) and serious injuries (SI) likely to be avoided, could potentially be avoided and are very unlikely to be avoided based on AEB- and LKA-supportive road infrastructure in Victoria, Queensland and South Australia, independent of remoteness level or road class.

\begin{tabular}{|c|c|c|c|c|c|c|c|c|c|c|c|c|c|c|c|}
\hline \multirow{2}{*}{\multicolumn{2}{|c|}{$\begin{array}{c}\text { Technology Type } \\
\text { Speed Zone } \\
\text { (Significance) }\end{array}$}} & \multicolumn{4}{|c|}{ AEB, Narrowly Sensitive } & \multicolumn{4}{|c|}{ AEB, Broadly Sensitive } & \multirow{2}{*}{\multicolumn{2}{|c|}{$\begin{array}{c}\text { AEB, } \\
\text { Pedestrian-Sensitive } \\
\leq 60 \mathrm{~km} / \mathrm{h} \\
p=0.62\end{array}$}} & \multicolumn{4}{|c|}{ LKA-Sensitive } \\
\hline & & \multicolumn{2}{|c|}{$\begin{array}{c}\leq 60 \mathrm{~km} / \mathrm{h} \\
p=0.09\end{array}$} & \multicolumn{2}{|c|}{$\begin{array}{c}>60 \mathrm{~km} / \mathrm{h} \\
p=0.008\end{array}$} & \multicolumn{2}{|c|}{$\begin{array}{c}\leq 60 \mathrm{~km} / \mathrm{h} \\
p=0.30\end{array}$} & \multicolumn{2}{|c|}{$\begin{array}{c}>60 \mathrm{~km} / \mathrm{h} \\
p=0.42\end{array}$} & & & \multicolumn{2}{|c|}{$\begin{array}{c}<100 \mathrm{~km} / \mathrm{h} \\
p=0.004\end{array}$} & \multicolumn{2}{|c|}{$\begin{array}{c}\geq 100 \mathrm{~km} / \mathrm{h} \\
p=0.004\end{array}$} \\
\hline & & $\mathbf{F}$ & SI & F & SI & $\mathbf{F}$ & SI & $\mathbf{F}$ & SI & $\mathbf{F}$ & SI & $\mathbf{F}$ & SI & F & SI \\
\hline \multirow{3}{*}{ Victoria } & avoided & $\begin{array}{l}0.56 \\
(0.47 \\
0.65)\end{array}$ & $\begin{array}{l}42.89 \\
(42.80 \\
42.98)\end{array}$ & $\begin{array}{l}1.23 \\
(1.01 \\
1.45)\end{array}$ & $\begin{array}{l}95.85 \\
(95.63 \\
96.07)\end{array}$ & $\begin{array}{l}1.08 \\
(1.04 \\
1.12)\end{array}$ & $\begin{array}{l}51.51 \\
(51.47 \\
51.55)\end{array}$ & $\begin{array}{l}3.53 \\
(3.50 \\
3.57)\end{array}$ & $\begin{array}{l}40.31 \\
(40.28 \\
40.35)\end{array}$ & $\begin{array}{l}1.70 \\
(1.33 \\
2.06)\end{array}$ & $\begin{array}{l}37.79 \\
(37.43 \\
38.15)\end{array}$ & $\begin{array}{l}1.24 \\
(1.21 \\
1.27)\end{array}$ & $\begin{array}{l}17.98 \\
(17.95 \\
18.01)\end{array}$ & $\begin{array}{l}4.65 \\
(4.62 \\
4.68)\end{array}$ & $\begin{array}{l}35.04 \\
(35.01 \\
35.06)\end{array}$ \\
\hline & $\begin{array}{l}\text { potentially } \\
\text { avoided }\end{array}$ & $\begin{array}{l}0.18 \\
(0.12 \\
0.24)\end{array}$ & $\begin{array}{l}12.64 \\
(12.59 \\
12.69) \\
\end{array}$ & $\begin{array}{l}0.30 \\
(0.17 \\
0.43)\end{array}$ & $\begin{array}{l}20.49 \\
(20.36 \\
20.61) \\
\end{array}$ & $\begin{array}{l}0.37 \\
(0.35 \\
0.38)\end{array}$ & $\begin{array}{l}15.37 \\
(15.35 \\
15.38) \\
\end{array}$ & $\begin{array}{l}1.15 \\
(1.14 \\
1.16)\end{array}$ & $\begin{array}{l}12.99 \\
(12.97 \\
13.00)\end{array}$ & $\begin{array}{l}0.54 \\
(0.44 \\
0.64)\end{array}$ & $\begin{array}{l}11.01 \\
(10.91 \\
11.11) \\
\end{array}$ & $\begin{array}{l}1.07 \\
(1.04 \\
1.09) \\
\end{array}$ & $\begin{array}{l}16.17 \\
(16.15 \\
16.20)\end{array}$ & $\begin{array}{l}4.54 \\
(4.52, \\
4.57)\end{array}$ & $\begin{array}{l}25.14 \\
(25.12, \\
25.16)\end{array}$ \\
\hline & unavoided & $\begin{array}{c}0.05 \\
(-0.20 \\
0.30)\end{array}$ & $\begin{array}{l}4.48 \\
(4.41 \\
4.55)\end{array}$ & $\begin{array}{c}0.12 \\
(-0.03 \\
0.27)\end{array}$ & $\begin{array}{l}4.49 \\
(4.32 \\
4.66)\end{array}$ & $\begin{array}{l}0.19 \\
(0.17 \\
0.22)\end{array}$ & $\begin{array}{l}7.10 \\
(7.07 \\
7.13)\end{array}$ & $\begin{array}{l}0.82 \\
(0.80 \\
0.85)\end{array}$ & $\begin{array}{l}8.36 \\
(8.34 \\
8.39)\end{array}$ & $\begin{array}{l}0.35 \\
(0.11 \\
0.58)\end{array}$ & $\begin{array}{l}5.14 \\
(4.91 \\
5.38)\end{array}$ & $\begin{array}{l}1.19 \\
(1.16 \\
1.23)\end{array}$ & $\begin{array}{l}20.31 \\
(20.28 \\
20.35)\end{array}$ & $\begin{array}{l}4.18 \\
(4.15 \\
4.22)\end{array}$ & $\begin{array}{l}28.98 \\
(28.95 \\
29.02)\end{array}$ \\
\hline \multirow{2}{*}{ Queensland } & avoided & $\begin{array}{c}0.33 \\
(0.23 \\
0.42)\end{array}$ & $\begin{array}{c}103.33 \\
(103.23 \\
103.42)\end{array}$ & $\begin{array}{l}1.43 \\
(1.34 \\
1.52)\end{array}$ & $\begin{array}{c}129.40 \\
(129.31 \\
129.49)\end{array}$ & $\begin{array}{l}1.01 \\
(0.97 \\
1.05)\end{array}$ & $\begin{array}{c}101.51 \\
(101.47, \\
101.55)\end{array}$ & $\begin{array}{l}3.98 \\
(3.94 \\
4.02)\end{array}$ & $\begin{array}{l}43.70 \\
(43.67 \\
43.74) \\
\end{array}$ & $\begin{array}{l}0.88 \\
(0.51 \\
1.25)\end{array}$ & $\begin{array}{l}14.02 \\
(13.65, \\
14.40)\end{array}$ & $\begin{array}{l}45.56 \\
(45.53, \\
45.59) \\
\end{array}$ & $\begin{array}{c}487.44 \\
(487.41 \\
487.48)\end{array}$ & $\begin{array}{l}7.80 \\
(7.77 \\
7.83)\end{array}$ & $\begin{array}{c}66.97 \\
(66.94, \\
67.01)\end{array}$ \\
\hline & unavoided & $\begin{array}{c}0.01 \\
(-0.05 \\
0.07)\end{array}$ & $\begin{array}{l}10.98 \\
(10.92, \\
11.04) \\
\end{array}$ & $\begin{array}{l}0.09 \\
(0.03 \\
0.15) \\
\end{array}$ & $\begin{array}{l}6.50 \\
(6.45 \\
6.56) \\
\end{array}$ & $\begin{array}{c}0.17 \\
(0.15 \\
0.19) \\
\end{array}$ & $\begin{array}{l}20.68 \\
(20.66 \\
20.71) \\
\end{array}$ & $\begin{array}{l}0.46 \\
(0.44 \\
0.48) \\
\end{array}$ & $\begin{array}{l}6.34 \\
(6.32, \\
6.36) \\
\end{array}$ & $\begin{array}{c}0.21 \\
(0.03 \\
0.40)\end{array}$ & $\begin{array}{l}2.81 \\
(2.63 \\
3.00) \\
\end{array}$ & $\begin{array}{c}24.77 \\
(24.74, \\
24.81) \\
\end{array}$ & $\begin{array}{c}207.18 \\
(207.14 \\
207.21)\end{array}$ & $\begin{array}{l}1.78 \\
(1.74, \\
1.83) \\
\end{array}$ & $\begin{array}{l}12.90 \\
(12.86, \\
12.94)\end{array}$ \\
\hline \multirow{3}{*}{$\begin{array}{c}\text { South } \\
\text { Australia }\end{array}$} & avoided & $\begin{array}{l}0.15 \\
(0.04 \\
0.27)\end{array}$ & $\begin{array}{l}5.13 \\
(5.01 \\
5.24)\end{array}$ & $\begin{array}{c}0.28 \\
(-0.01 \\
0.56)\end{array}$ & $\begin{array}{l}5.65 \\
(5.37 \\
5.94)\end{array}$ & $\begin{array}{c}0.32 \\
(0.27 \\
0.37)\end{array}$ & $\begin{array}{l}5.95 \\
(5.90 \\
5.99)\end{array}$ & $\begin{array}{l}3.26 \\
(3.22, \\
3.30)\end{array}$ & $\begin{array}{l}40.70 \\
(40.66 \\
40.74)\end{array}$ & $\begin{array}{c}0.06 \\
(-0.37 \\
0.48)\end{array}$ & $\begin{array}{c}0.29 \\
(-0.16 \\
0.75)\end{array}$ & $\begin{array}{l}0.44 \\
(0.41 \\
0.47)\end{array}$ & $\begin{array}{l}2.77 \\
(2.73 \\
2.80)\end{array}$ & $\begin{array}{l}2.86 \\
(2.82, \\
2.89)\end{array}$ & $\begin{array}{l}10.17 \\
(10.14, \\
10.20)\end{array}$ \\
\hline & $\begin{array}{l}\text { potentially } \\
\text { avoided }\end{array}$ & $\begin{array}{c}0.03 \\
(-0.03 \\
0.09)\end{array}$ & $\begin{array}{c}0.95 \\
(0.89 \\
1.01) \\
\end{array}$ & $\begin{array}{c}0.03 \\
(-0.13 \\
0.19)\end{array}$ & $\begin{array}{c}0.84 \\
(0.68 \\
1.00) \\
\end{array}$ & $\begin{array}{c}0.05 \\
(0.03 \\
0.07)\end{array}$ & $\begin{array}{l}1.03 \\
(1.01 \\
1.04)\end{array}$ & $\begin{array}{c}0.52 \\
(0.51 \\
0.53)\end{array}$ & $\begin{array}{c}6.51 \\
(6.50 \\
6.52) \\
\end{array}$ & $\begin{array}{c}0.00 \\
(-0.11 \\
0.12)\end{array}$ & $\begin{array}{c}0.05 \\
(-0.06 \\
0.16)\end{array}$ & $\begin{array}{c}0.16 \\
(0.14 \\
0.18)\end{array}$ & $\begin{array}{l}1.34 \\
(1.32, \\
1.36)\end{array}$ & $\begin{array}{c}0.43 \\
(0.41 \\
0.45)\end{array}$ & $\begin{array}{l}2.21 \\
(2.19, \\
2.23)\end{array}$ \\
\hline & unavoided & $\begin{array}{c}0.00 \\
(-0.08 \\
0.08)\end{array}$ & $\begin{array}{l}0.50 \\
(0.42, \\
0.58)\end{array}$ & $\begin{array}{c}0.07 \\
(-0.13 \\
0.26)\end{array}$ & $\begin{array}{l}0.78 \\
(0.59 \\
0.98)\end{array}$ & $\begin{array}{l}0.05 \\
(0.02 \\
0.07)\end{array}$ & $\begin{array}{l}0.79 \\
(0.76 \\
0.82)\end{array}$ & $\begin{array}{l}0.30 \\
(0.28 \\
0.33)\end{array}$ & $\begin{array}{l}2.62 \\
(2.60, \\
2.64)\end{array}$ & $\begin{array}{c}0.00 \\
(-0.24 \\
0.25)\end{array}$ & $\begin{array}{c}0.02 \\
(-0.23 \\
0.26)\end{array}$ & $\begin{array}{l}1.23 \\
(1.20 \\
1.25)\end{array}$ & $\begin{array}{l}2.33 \\
(2.30 \\
2.36)\end{array}$ & $\begin{array}{l}0.75 \\
(0.72 \\
0.78)\end{array}$ & $\begin{array}{l}3.94 \\
(3.91, \\
3.96)\end{array}$ \\
\hline
\end{tabular}


The majority of fatalities and serious injuries that occur from AEB and LKA-sensitive crashes across all three states appear likely to be prevented by the new technologies, based on available road infrastructure. In Victoria, while over 22 fatalities and 434 serious injuries appear likely to be prevented, close to 7 fatalities and 79 serious injuries appear unpreventable based on existing road infrastructure. The trends are similar in Queensland with over 85 fatalities and 1260 serious injuries likely prevented based on existing road quality, but 27 fatalities and 267 serious injuries are unlikely to be avoided, due to either poor quality bitumen or unsealed roads, or a lack of delineation. Though comparatively less in South Australia (over 8 fatalities and 84 serious injuries likely prevented), the trend is similar, with close to 3 fatalities and 11 serious injuries unlikely to be prevented, due to poor road quality. Of the crashes that are unlikely to be avoided in each state, the greatest fatality and serious injuries figures are those likely to result from LKA-sensitive crashes. Of the fatalities and serious injuries not prevented, in Victoria, $60 \%$ of fatalities and almost $40 \%$ of serious injuries are predicted to be from LKA-sensitive crashes that occur in high-speed zones. Interestingly, in Queensland 90\% of fatalities and almost 78\% of serious injuries are predicted to be from LKA-sensitive crashes that occur in low-speed zones (i.e., $<100 \mathrm{~km} / \mathrm{h}$ ), with these figures being much less in South Australia (with 51\% of fatalities and $21 \%$ of serious injuries unavoided being from LKA-sensitive crashes in low-speed zones). Across the three states (Victoria, Queensland and South Australia), of the fatalities that are likely to occur in AEB- and LKA-sensitive crashes, almost $24 \%, 24 \%$ and $21 \%$ of fatalities (respectively) are unlikely to be avoided while almost $15 \%, 17 \%$ and $12 \%$ of serious injuries (respectively across each state) are unlikely to be avoided due to poor road infrastructure.

\section{Discussion}

The objective of this study was to estimate the lost benefits of AEB and LKA technologies due to inadequate road infrastructure, by estimating the proportion of roads that are unlikely to support emerging ADAS technologies such as AEB and LKA, and therefore unlikely to prevent AEB- and LKA-sensitive fatalities and serious injuries. To do this, the road classes and remoteness levels across Victoria, Queensland and South Australia were used to distinguish between state-maintained roads (high-quality roads, such as freeways and highways) and council-maintained roads (such as local roads and streets). The readiness of the roads (across road classes and remoteness levels) to support AEB and LKA was estimated by identifying the proportion of AEB- and LKA-sensitive FSI crashes that are likely to occur on the roads (based on historical crash data from Victoria, South Australia and Queensland), combined with the most recent and relevant AEB and LKA effectiveness estimates identified from the literature, applied to the historical FSI figures. Using this methodology and assuming that all vehicles in future will be fitted with AEB and LKA, the number of fatalities and serious injuries resulting from AEB- and LKA-sensitive crash types, which are unlikely to be avoided annually due to inadequate road infrastructure, were estimated, and the lost benefits of AEB and LKA identified.

\subsection{AEB-Supportive Roads}

Freeways and highways in the three states considered here, were found to be consistently sealed, with high-quality bitumen across all environments. Conversely, local roads, collector or connector roads (in all three states) was found to have bitumen of questionable quality, with a large proportion of unsealed roads. Specifically, the analysis demonstrated that approximately $73 \%, 60 \%$ and $95 \%$ of local roads in regional and remote regions in Victoria, Queensland and South Australia were unsealed. On these roads, not only is AEB performance likely to be compromised, but crash risk is likely to be higher [74,75]. On high volume roads, where AEB-sensitive crashes appear most likely (based on historical data), the roads appeared highly likely to support AEB technology. That is, across the three states, over $71 \%, 53 \%$ and $94 \%$ of all FSI AEB-sensitive crashes (i.e., light vehicles, AEB narrowly, broadly, pedestrian-sensitive, and AEB heavy vehicles), historically occurred on freeways, 
highways, arterial and sub-arterial roads (or equivalent), where the bitumen quality was consistently high. Interestingly, in Queensland, approximately 50\% of each AEB-sensitive crash type occurred on local connector roads and streets where roads were frequently unsealed and of average quality. Given this, the estimated number of fatalities and serious injuries that would likely be avoided on Queensland roads would be less than in Victoria and South Australia. Assuming all vehicles are fitted with AEB in future, in Queensland alone, it was estimated that annually, over 14 fatalities and serious injuries would continue to occur in AEB-narrowly-sensitive crashes $(p=0.09)$, more than 25 fatalities and serious injuries would continue to occur in AEB broadly sensitive crash types $(p=0.42)$, and more than 3 FSI crashes would occur as a result of pedestrian-sensitive AEB crashes $(p=0.62)$ where roads are lacking AEB supportive infrastructure.

\subsection{LKA-Supportive Roads}

While the presence of quality bitumen sealed roads appeared fairly consistent across the three states, there was a larger contrast between road classes and remoteness levels and across the states when delineation was used as a proxy to gauge LKA-supportive roads. While only one third of the four major road classes in Victoria (freeways, highways, arterial and sub arterial roads) had poor quality delineation or no delineation, more than $90 \%$ of collector roads and local roads across the state had no delineation that would be detected by most LKA technologies. The delineation quality analysis highlighted similar deficiencies in Queensland, where 22\% of highways, freeways and secondary roads were of poor quality, but more than $77 \%$ of local connector roads and streets lacked delineation; and South Australia, where $28 \%$ of the major four road classes had poor quality delineation but close to $84 \%$ of collector and local roads lacked delineation. Despite this, given that most LKA systems, at present, only function at speeds of above $65 \mathrm{~km} / \mathrm{h}$, delineation availability across local roads and streets were not considered when estimating the number of fatalities and serious injuries that may/may not be avoided, since local roads and streets are typically signed at $50 \mathrm{~km} / \mathrm{h}$.

Historical crash data suggests that the majority of fatalities and serious injuries that result from LKA-sensitive crashes occur in high-speed zones. Annually, over 470 and 560 LKA-sensitive crashes occurring in Victoria and Queensland did so across their four major road networks, while $48 \%$ to $66 \%$ of these crashes occurred on freeways and highways, where roads were found to have high-quality delineation. Annually, close to 300 FSI LKAsensitive crashes occurred in low-speed zones $(<100 \mathrm{~km} / \mathrm{h})$ across the major networks in the same states, with approximately $25-30 \%$ of these occurring on freeways and highways where delineation was assessed to be adequate, based on satellite imagery alone. While the proportions of high-speed and low-speed-sensitive LKA-sensitive crashes occurring on the major network was similar in South Australia, the number of crashes was comparatively less. Across the three states, close to $50 \%$ of LKA-sensitive crashes have historically occurred on arterial, and sub-arterial (or equivalent roads), where delineation was found to be less than adequate, potentially compromising the ability of LKA function, once all vehicles are fitted with the technology. Based on the LKA-sensitive crashes in the historical crash data, up to 138 fatalities and 142 serious injuries may not be avoided annually across the three Australian states based on lack of delineation availability.

Delineation has been previously shown to be an important road feature for vehicles fitted with lane keep assist $[34,47,48]$. Studies have shown that when delineation is of poor quality or altogether absent, LKA assist can fail, given the sensors within the vehicle fail to gauge the intended path of the vehicle [47-49]. Despite this, the effectiveness of the technology has often been described as being high [21]. LKA is predicted to prevent run off road impacts, head on impacts and loss of control impacts, assuming the delineation is detected by the sensors $[18,21,38]$. The current study found that of the road classes in three Australian states, a large majority of sub-arterial and collector roads in Victoria and South Australia, and equivalent collector roads in Queensland, particularly in regional and remote areas, lacked adequate delineation and would be unlikely to support LKA 
technologies. Therefore, even if all vehicles are fitted with LKA technologies, it is likely that where delineation quality is lacking, road crash fatalities and serious injuries will continue to occur.

\subsection{Limitations and Other Considerations}

The results reported in this study should be considered in light of some limitations that are outlined herein.

1. AEB and LKA may be sensitive to adverse weather conditions, including excessive glare or snow/ice [76-78]. In this study, the crash population was defined as those crashes that could be mitigated by AEB and LKA where the weather conditions were appropriate for the technology to work. LKA-sensitive crashes that occurred in snow or ice, for example, were excluded from our analysis (see Supplementary Table S79). The effects of glare, however, were difficult to exclude from the sensitive crash population since it is not readily reported in the crash data. The effects of glare on LKA-sensitive crashes were therefore not taken into account in the analysis.

2. Minor injury and property damage crashes, which make up a large proportion of crashes that are sensitive to AEB and LKA technologies, were not considered here. The lost benefits of the technologies due to inadequate infrastructure, therefore, are likely to be much greater when all crash types are considered.

3. While historical crash data was used in this study to estimate future lost benefits, caution should be exercised if assuming these crash trends will continue into the future. In the analyses presented in this study, it was presumed that all other parameters remained constant over time: e.g., driver behaviour, fleet size and road infrastructure.

4. While the proportion of heavy vehicle crashes sensitive to AEB were considered in this study, the numbers of heavy vehicle crashes that fit the AEB sensitivity criteria over the six-year period investigated were low in number and, therefore, not discussed throughout. Using a larger data set or relaxing the AEB-sensitivity criteria for heavy vehicle crashes will be considered in future studies.

5. Similarly, the proportion of pedestrian-sensitive crashes over the six-year period was low, particularly when disaggregating the number of pedestrian-sensitive crashes by speed zone. Given the pedestrian-sensitive AEB crash effectiveness values for high-speed crashes noted by Newstead and researchers [30] were not statistically significant, these values were also disregarded when looking at the ability of the road network to support pedestrian-sensitive crashes in high-speed zones.

6. When estimating the fatalities and serious injuries sensitive to the technologies, it was assumed that no vehicle in the historical crash dataset was fitted with AEB- and LKA. When estimating the number of fatalities and serious injuries likely avoided in future, it was assumed that all vehicles will be fitted with AEB and LKA technologies. Although this was a gross assumption made in order to approximate lost benefits, the current absence of these technologies in the fleet is not highly unrealistic given the current age of the vehicle fleets in the states of Victoria, Queensland and South Australia and the rate of AEB and LKA fitment in the fleet of vehicles between 2013 and 2018 (i.e., the historical data used in this study). Further, previous research suggests that during 2013 to 2015 , less than $0.1 \%$ of crashed light vehicles were models with AEB fitted to all variants of the model. This assumption therefore is unlikely to bias the potential benefits estimated [30].

7. The fatality and serious injury figures avoided/unavoided due to the supportive road infrastructure presented in this study, represent approximations based on three of Australia's most urbanized states, and caution should be exercised if projecting these figures to national estimates given the larger rural road networks in states such as the North Territory and Western Australia.

In this study, results are presented separately for each of the three states. While it would have been simpler to aggregate results and obtain a national projection of roadreadiness for each of the technologies considered, this could not be done due to the incon- 
sistent way in which roads are categorised and maintained in each of the states (discussed earlier). This methodology, however, can be applied to crash data in other states to determine the level of road-readiness to support AEB and LKA.

\subsection{Future Directions}

This is the first study, to our knowledge, that has attempted to quantify how prepared the road network is for supporting AEB and LKA technologies. While multiple studies have attempted to do this through real-world experiments [8,21,79] or simulations [80-82], it is impossible to project such findings to a state or Country level, due to the unique and expansive nature of the road network across states and Territories in Australia and in other countries. The methodology used here, can be employed to identify the preparedness of road networks in other states or countries to support specific ADAS technologies, as well as for quantifying the benefits of the technologies that are likely to be foregone due to unsupportive road infrastructure.

\section{Conclusions}

In this study we quantified what proportion of the crash population that is assumed to be mitigated by AEB and LKA, will actually not be mitigated due to absent road infrastructure. Based on historical crash data, annually, approximately to 8 deaths and 79 serious injuries in Victoria, 27 deaths and 267 serious injuries in Queensland and 2 deaths and 11 serious injuries in South Australia will continue to result from AEB- and LKA-sensitive crashes due to unavailable road infrastructure. Collector and local roads in Victoria and Queensland in particular, appear to be the least likely to support AEB while arterial and sub-arterials (or equivalents) appear to be least supportive of LKA technologies. Due to the highly variable nature of roads in Victoria, Queensland and South Australia to support AEB and LKA technologies, it is inevitable that deaths and serious injuries will continue to occur in AEB- and LKA-sensitive crashes due to the absence of consistently available supportive road infrastructure. The implications of road quality and its impact on technology effectiveness should be considered in future studies when the benefits of ADAS technologies are reported.

For now, investments are required in appropriate provision and maintenance of high-volume road delineation such as arterial and sub-arterial roads (or equivalents) in particular since $13-23 \%$ of all FSI crashes that occur on these roads are generally LKAsensitive. Given that AEB and LKA technologies are being actively promoted, and the inclusion of these technologies in new vehicles are being mandated globally, it is important that high-volume roads are concurrently improved to support these technologies as a priority. Future research will identify if these trends are the same across the other states in Australia and New Zealand, and if so, how infrastructure investment should be targeted to optimize the ability of the technology to function properly. Now is the time for these road investments to be considered, prioritised and allocated.

Supplementary Materials: The following supporting information can be downloaded at: https: / / www.mdpi.com/article/10.3390/su14042234/s1, More information can be seen in Tables S1-S79, Figures S1 and S2. Reference [83] is cited in supplementary material.

Author Contributions: Conceptualization, S.N., S.P., J.B.-G. and B.F.; Methodology, S.N. and S.P.; Formal Analysis, S.P. and S.N.; Investigation, S.P.; Resources, J.B.-G. and B.F.; Data Curation, S.P.; Writing-Original Draft Preparation, S.P. and J.B.-G.; Writing-Review and Editing, S.P., S.N., J.B.-G. and B.F.; Supervision, S.N., J.B.-G., B.C. and B.F.; Project Administration, S.P. and J.B.-G. All authors have read and agreed to the published version of the manuscript.

Funding: This research received no external funding.

Institutional Review Board Statement: Not applicable.

Informed Consent Statement: Not applicable. 
Data Availability Statement: Not applicable.

Conflicts of Interest: The authors declare no conflict of interest.

\section{References}

1. Singh, S. Critical Reasons for Crashes Investigated in the National Motor Vehicle Crash Causation Survey; NHTSA's National Center for Statistics and Analysis: Washington, DC, USA, 2015; pp. 1-2.

2. Spicer, R.; Vahabaghaie, A.; Bahouth, G.; Drees, L.; Martinez von Bülow, R.; Baur, P. Field effectiveness evaluation of advanced driver assistance systems. Traffic Inj. Prev. 2018, 19, S91-S95. [CrossRef] [PubMed]

3. Seacrist, T.; Douglas, E.C.; Graci, V.; Loeb, H.S.; Sahani, R.; Chingas, G. Evaluation of AEB effectiveness using counterfactual simulations of SHRP2 naturalistic crashes. In Proceedings of the 26th International Technical Conference on the Enhanced Safety of Vehicles (ESV): Technology: Enabling a Safer Tomorrow, Eindhoven, The Netherlands, 10-13 June 2019; National Highway Traffic Safety Administration: Washington, DC, USA, 2019.

4. Sander, U.; Lubbe, N. Market penetration of intersection AEB: Characterizing avoided and residual straight crossing path accidents. Accid. Anal. Prev. 2018, 115, 178-188. [CrossRef] [PubMed]

5. Cicchino, J.B. Effects of lane departure warning on police-reported crash rates. J. Saf. Res. 2018, 66, 61-70. [CrossRef] [PubMed]

6. Cicchino, J.B. Effectiveness of forward collision warning and autonomous emergency braking systems in reducing front-to-rear crash rates. Accid. Anal. Prev. 2017, 99, 142-152. [CrossRef]

7. Isaksson-Hellman, I.; Lindman, M. Traffic Safety Benefit of A Lane Departure Warning System-A Retrospective Assessment of the Crash Avoidance Effect Based on Real World Crash Data in Sweden. Int. J. Automot. Eng. 2018, 9, 289-295. [CrossRef]

8. Fildes, B.; Keall, M.; Bos, N.; Lie, A.; Page, Y.; Pastor, C.; Pennisi, L.; Rizzi, M.; Thomas, P.; Tingvall, C. Effectiveness of low speed autonomous emergency braking in real-world rear-end crashes. Accid. Anal. Prev. 2015, 81, 24-29. [CrossRef]

9. Rizzi, M.; Kullgren, A.; Tingvall, C. Injury crash reduction of low-speed Autonomous Emergency Braking (AEB) on passenger cars. In Proceedings of the IRCOBI Conference on Biomechanics of Impacts, Berlin, Germany, 10-12 September 2014; pp. 14-73.

10. Haus, S.H.; Anderson, R.M.; Sherony, R.; Gabler, H.C. Potential Effectiveness of Bicycle-Automatic Emergency Braking using the Washtenaw Area Transportation Study Data Set. Transp. Res. Rec. 2021, 03611981211001377. [CrossRef]

11. Haus, S.H.; Sherony, R.; Gabler, H.C. Estimated benefit of automated emergency braking systems for vehicle-pedestrian crashes in the United States. Traffic Inj. Prev. 2019, 20, S171-S176. [CrossRef]

12. Chajmowicz, H.; Saadé, J.; Cuny, S. Prospective assessment of the effectiveness of autonomous emergency braking in car-to-cyclist accidents in France. Traffic Inj. Prev. 2019, 20, S20-S25. [CrossRef]

13. Saadé, J.; Chajmowicz, H.; Cuny, S. Prospective Evaluation of the Effectiveness of Autonomous Emergency Braking Systems in Increasing Pedestrian Road Safety in France. In Proceedings of the IRCOBI Conference, Florence, Italy, 11-13 September 2019.

14. Jeppsson, H.; Östling, M.; Lubbe, N. Real life safety benefits of increasing brake deceleration in car-to-pedestrian accidents: Simulation of Vacuum Emergency Braking. Accid. Anal. Prev. 2018, 111, 311-320. [CrossRef]

15. Scanlon, J.M.; Sherony, R.; Gabler, H.C. Injury mitigation estimates for an intersection driver assistance system in straight crossing path crashes in the United States. Traffic Inj. Prev. 2017, 18, S9-S17. [CrossRef] [PubMed]

16. Scanlon, J.M.; Sherony, R.; Gabler, H.C. Preliminary potential crash prevention estimates for an Intersection Advanced Driver Assistance System in straight crossing path crashes. In Proceedings of the 2016 IEEE Intelligent Vehicles Symposium (IV), Gothenburg, Sweden, 19-22 June 2016; pp. 1135-1140.

17. Scanlon, J.M.; Kusano, K.D.; Sherony, R.; Gabler, H.C. Potential safety benefits of lane departure warning and prevention systems in the US vehicle fleet. In Proceedings of the 24th International Technical Conference on the Enhanced Safety of Vehicles (ESV), Gothenburg, Sweden, 8-11 June 2015.

18. Penmetsa, P.; Hudnall, M.; Nambisan, S. Potential safety benefits of lane departure prevention technology. IATSS Res. 2019, 43, 21-26. [CrossRef]

19. Kusano, K.D.; Gabler, H.C. Comparison of expected crash and injury reduction from production forward collision and lane departure warning systems. Traffic Inj. Prev. 2015, 16, S109-S114. [CrossRef] [PubMed]

20. Kusano, K.; Gorman, T.I.; Sherony, R.; Gabler, H.C. Potential occupant injury reduction in the US vehicle fleet for lane departure warning-equipped vehicles in single-vehicle crashes. Traffic Inj. Prev. 2014, 15, S157-S164. [CrossRef]

21. Sternlund, S.; Strandroth, J.; Rizzi, M.; Lie, A.; Tingvall, C. The effectiveness of lane departure warning systems-A reduction in real-world passenger car injury crashes. Traffic Inj. Prev. 2017, 18, 225-229. [CrossRef]

22. Sternlund, S. The safety potential of lane departure warning systems-A descriptive real-world study of fatal lane departure passenger car crashes in Sweden. Traffic Inj. Prev. 2017, 18, S18-S23. [CrossRef]

23. Lai, F.; Carsten, O.; Tate, F. How much benefit does Intelligent Speed Adaptation deliver: An analysis of its potential contribution to safety and environment. Accid. Anal. Prev. 2012, 48, 63-72. [CrossRef]

24. Peiris, S.; Berecki-Gisolf, J.; Newstead, S.; Chen, B.; Fildes, B. Development of a Methodology for Estimating the Availability of ADAS-Dependent Road Infrastructure. Sustainability 2021, 13, 9512. [CrossRef]

25. J3016_201806; Taxonomy and Definitions for Terms Related to Driving Automation Systems for On-Road Motor Vehicles J3016_201806; SAE: Warrendale, PA, USA, 2016; Volume J3016, pp. 1-35. 
26. Yue, L.; Abdel-Aty, M.; Wu, Y.; Wang, L. Assessment of the safety benefits of vehicles' advanced driver assistance, connectivity and low level automation systems. Accid. Anal. Prev. 2018, 117, 55-64. [CrossRef]

27. Lubbe, N.; Jeppsson, H.; Ranjbar, A.; Fredriksson, J.; Bärgman, J.; Östling, M. Predicted road traffic fatalities in Germany: The potential and limitations of vehicle safety technologies from passive safety to highly automated driving. In Proceedings of the IRCOBI Conference, Athena, Greece, 12-14 September 2018.

28. Lubbe, N.; Thalya, P.; Puthan, P.; Boström, O.; Global Road Traffic Fatality Estimate for 2060: The Effect of Increased Vehicle Automation. IRCOBI Asia 2020. pp. 3-6. Available online: http://www.ircobi.org/wordpress/downloads/irc20-asia/pdf-files/ 2010a.pdf (accessed on 14 August 2021).

29. da Silva, J.F.; Nunes, R.V. Traffic accident reduction potential and economic impact-automotive safety items. In Proceedings of the AEA-Brazilian Society of Automotive Engineering, São Paulo, Brazil, 17-18 March 2021; p. 8.

30. Newstead, S.; Budd, L.; Stephens, A. The Potential Benefits of Autonomous Emergency Braking Systems in Australia; 1925413098; Monash University Accident Research Centre: Melbourne, Australia, 2020; pp. 1-116.

31. ANCAP. ANCAP Assessment Protocol: Safety Assist v9.0.3; ANCAP: Manuka, Australia, 2020; p. 28.

32. Tian, J.; Liu, S.; Zhong, X.; Zeng, J. LSD-based adaptive lane detection and tracking for ADAS in structured road environment. Soft Comput. 2021, 25, 5709-5722. [CrossRef]

33. Mishra, M.; Kumar, A. ADAS Technology: A Review on Challenges, Legal Risk Mitigation and Solutions. In Autonomous Driving and Advanced Driver-Assistance Systems (ADAS); CRC Press: Boca Raton, FL, USA, 2021; pp. 401-408.

34. Mackenzie, J.; Dutschke, J.; van den Berg, A.; Kumar, M.; Meuleners, L. Automated Vehicles and the Readiness of Western Australian Roads; Curtin University: Bentley, Australia, 2018.

35. Benson, A.J.; Tefft, B.C.; Svancara, A.M.; Horrey, W.J. Potential Reductions in Crashes, Injuries, and Deaths from Large-Scale Deployment of Advanced Driver Assistance Systems; Research Brief; AAA Foundation for Traffic Safety: Washington, DC, USA, 2018.

36. Tan, H.; Zhao, F.; Hao, H.; Liu, Z.; Amer, A.A.; Babiker, H. Automatic emergency braking (AEB) system impact on fatality and injury reduction in China. Int. J. Environ. Res. Public Health 2020, 17, 917. [CrossRef]

37. Budd, L.; Newstead, S.; D'Elia, A. Identifying Future Vehicle Safety Priority Areas in Australia for the Light Vehicle Fleet; Monash University Accident Research Centre Report: Melbourne, Australia, 2020.

38. Newstead, S.; Watson, L.; Budd, L. The Potential Benefits of Lane Keep Assist Systems in Australian Light Vehicles; Monash University: Melbourne, Australia, 2021.

39. Savino, G.; Mackenzie, J.; Allen, T.; Baldock, M.; Brown, J.; Fitzharris, M. A robust estimation of the effects of motorcycle autonomous emergency braking (MAEB) based on in-depth crashes in Australia. Traffic Inj. Prev. 2016, 17, 66-72. [CrossRef]

40. Euro NCAP. Euro NCAP Test Protocol-AEB Car-to-Car Systems; Version 3.0.3; Euro NCAP: Brussels, Belgium, 2021; pp. 1-28.

41. TNO Human Factors Guidelines Report 2: Driver Support Systems Overview; TNO: Helmond, The Netherlands, $2021 ;$ p. 62.

42. Isaksson-Hellman, I.; Lindman, M. Evaluation of the crash mitigation effect of low-speed automated emergency braking systems based on insurance claims data. Traffic Inj. Prev. 2016, 17, 42-47. [CrossRef]

43. Anderson, R.; Hutchinson, T.; Linke, B.; Ponte, G. Analysis of Crash Data to Estimate the Benefits of Emerging Vehicle Technology; Centre for Automotive Safety Research, The University of Adelaide: Adelaide, Australia, 2010.

44. European Union Regulation (EU) 2019/2144 of the European Parliament and of the Council; Amendment of Regulation (EU) 2018/858; EU: Brussels, Belgium, 2019; Volume 2144.

45. Federal Register of Legislation. Vehicle Standard (Australian Design Rule 98/00-Advanced Emergency Braking for Passenger Vehicles and Light Goods Vehicles) 2021; Federal Register of Legislation: Canberra, Australia, 2021; Volume F2021L01518, p. 36.

46. Department of Infrastructure, Transport, Regional Development and Communications. Regulation Impact Statement: Lane Keeping Systems for Light Vehicles; Vehicle Standards Report 13/2021; Australian Government: Canberra, Australia, 2021 ; p. 65.

47. Transurban. NSW Partially Automated Vehicle Trials. Stage One-Sydney Orbital Network; Transurban: Melbourne, Australia, 2018; p. 26.

48. Transurban. Victorian Connected and Automated Vehicle Trials Program: Phase One; Transurban: Melbourne, Australia, 2018 ; p. 26.

49. Germanchev, A.; Eastwood, B.; Hore-Lacy, W. Infrastructure Changes to Support Automated Vehicles on Rural and Metropolitan Highways and Freeways Road Audit (Module 2); Austroads Ltd.: Sydney, Australia, 2019; p. 90.

50. Road Safety Taskforce. Review of National Road Safety Governance Arrangements, Final Report; Australian Government: Canberra, Australia, 2019.

51. Jurewicz, C.; Steinmetz, L.; Turner, B. Australian National Risk Assessment Model; Austroads Ltd.: Sydney, Australia, $2014 ;$ p. 82.

52. Buchanan, K. National Funding of Road Infrastructure Australia; Law Library of Congress, Library of Congress: Washington, DC, USA, 2014.

53. Australian Local Government Association Roads Funding. Available online: https://alga.asn.au/policy-centre/roads-andinfrastructure/roads-funding/ (accessed on 21 April 2021).

54. Peiris, S.; Berecki-Gisolf, J.; Chen, B.; Fildes, B. Road Trauma in Regional and Remote Australia and New Zealand in Preparedness for ADAS Technologies and Autonomous Vehicles. Sustainability 2020, 12, 4347. [CrossRef]

55. Austroads. Guide to Road Safety Part 5: Road Safety for Regional and Remote Areas; Department of Transport and Main Roads: Sydney, Australia, 2019; p. 66. 
56. Australian Bureau of Statistics 1270.0.55.004-Australian Statistical Geography Standard (ASGS): Volume 4-Significant Urban Areas, Urban Centres and Localities, Section of State. Available online: https:/ /www.abs.gov.au/ausstats/abs@.nsf/Lookup/ by\%20Subject/1270.0.55.004 \{\}July\%202016 \{\}Main\%20Features \{\}Significant\%20Urban\%20Area\%20(SUA) \{\}5 (accessed on 17 September 2019).

57. ABS. The Australian Statistical Geography Standard (ASGS) Remoteness Structure: Map of the 2016 Remoteness Areas for Australia. Available online: https://www.abs.gov.au/websitedbs/D3310114.nsf/home/remoteness+structure (accessed on 13 September 2019).

58. Department of Planning Transport and Infrastructure. Road Classification Guidelines in South Australia; Local Government Association of South Australia: Canberra, Australia, 2018; p. 18.

59. State of Queensland Transport Infrastructure Act 1994; State of Queensland Parliamentary Counsel: City East, Qld, Australia, 1994; p. 632, Current as at 21 July 2020.

60. Transport and Main Roads. Different Types of Roads and Their Purpose; The Department of Transport and Main Roads: Brisbane, Australia, 2020.

61. Road Management Act 2004; Authorised Version No. 061 (No. 12 of 2004); Chief Parliamentary Counsel: Melbourne, VIC, Australia, 2021; p. 306.

62. McHugh, M.L. Interrater reliability: The kappa statistic. Biochem. Med. 2012, 22, 276-282. [CrossRef]

63. Glassbrenner, D.; Morgan, A.; Kreeb, R.; Svenson, A.; Liddell, H.; Barickman, F. A Target Population for Automatic Emergency Braking in Heavy Vehicles; National Highway Traffic Safety Administration: Washington, DC, USA, 2017.

64. Salaani, M.K.; Elsasser, D.; Boday, C. Heavy Vehicles Kinematics of Automatic Emergency Braking Test Track Scenarios; 0148-7191 SAE Technical Paper; SAE: Warrendale, PA, USA, 2020.

65. Salaani, M.K.; Elsasser, D.; Boday, C. NHTSA's 2018 Heavy Vehicle Automatic Emergency Braking Test Track Research Results. SAE Int. J. Adv. Curr. Pract. Mobil. 2020, 2, 1685-1704. [CrossRef]

66. VicRoads. Definitions for Classifying Accidents. 2013. Available online: https://vicroadsopendatastorehouse.vicroads.vic.gov. au/opendata/Road_Safety/DCA_Chart_and_Sub_DCA_Codes.PDF (accessed on 21 August 2021).

67. Edwards, M.; Nathanson, A.; Wisch, M. Estimate of potential benefit for Europe of fitting autonomous emergency braking (AEB) systems for pedestrian protection to passenger cars. Traffic Inj. Prev. 2014, 15, S173-S182. [CrossRef]

68. Ohlin, M.; Strandroth, J.; Tingvall, C. The combined effect of vehicle frontal design, speed reduction, autonomous emergency braking and helmet use in reducing real life bicycle injuries. Saf. Sci. 2017, 92, 338-344. [CrossRef]

69. Sander, U. Opportunities and limitations for intersection collision intervention-A study of real world 'left turn across path'accidents. Accid. Anal. Prev. 2017, 99, 342-355. [CrossRef]

70. Silla, A.; Rämä, P.; Leden, L.; Van Noort, M.; de Kruijff, J.; Bell, D.; Morris, A.; Hancox, G.; Scholliers, J. Quantifying the effectiveness of ITS in improving safety of VRUs. IET Intell. Transp. Syst. 2017, 11, 164-172. [CrossRef]

71. Sander, U.; Lubbe, N.; Pietzsch, S. Intersection AEB implementation strategies for left turn across path crashes. Traffic Inj. Prev. 2019, 20, S119-S125. [CrossRef] [PubMed]

72. Woodrooffe, J.; Blower, D.; Bao, S.; Bogard, S.; Flannagan, C.; Green, P.E.; LeBlanc, D. Final Report: Performance Characterization and Safety Effectiveness Estimates of Forward Collision Avoidance and Mitigation Systems for Medium/Heavy Commercial Vehicles; National Highway Traffic Safety Administration: Washington, DC, USA, 2012.

73. Australian Bureau of Statistics Motor Vehicle Census, Australia. 2021. Available online: https://www.abs.gov.au/statistics/ industry/tourism-and-transport/motor-vehicle-census-australia/latest-release (accessed on 30 June 2021).

74. Boschert, L.; Pyta, V.; Turner, B.; Green, D. Road Safety Engineering Risk Assessment, Part 5: Review of Crashes on Unsealed Roads; 1921709057; Austroads: Sydney, Australia, 2010; p. 89.

75. Papadimitriou, E.; Filtness, A.; Theofilatos, A.; Ziakopoulos, A.; Quigley, C.; Yannis, G. Review and ranking of crash risk factors related to the road infrastructure. Accid. Anal. Prev. 2019, 125, 85-97. [CrossRef]

76. Wang, X.; Wang, J.; Sun, W.; Wang, Y.; Xie, F.; Guo, D. Development of AEB control strategy for autonomous vehicles on snow-asphalt joint pavement. Int. J. Crashworthiness 2021, 1-21. [CrossRef]

77. Pike, A.M.; Barrette, T.P.; Carlson, P.J. Evaluation of the Effects of Pavement Marking Characteristics on Detectability by ADAS Machine Vision; National Cooperative Highway Research Program (NCHRP): Washington, DC, USA, 2018.

78. Sauter, G.; Doring, M.; Nuyttens, R. High Performance Pavement Markings Enhancing Camera And LiDAR Detection. In Proceedings of the IOP Conference Series: Materials Science and Engineering, Riga, Latvia, 23-24 August 2021 ; p. 012033.

79. Doyle, M.; Edwards, A.; Avery, M. AEB real world validation using UK motor insurance claims data. In Proceedings of the Proceedings of the 24th ESV Conference, Gothenburg, Sweden, 8-11 June 2015; pp. 13-58.

80. Anderson, R.; Doecke, S.; Mackenzie, J.; Ponte, G. Potential benefits of autonomous emergency braking based on in-depth crash reconstruction and simulation. In Proceedings of the 23rd International Conference on Enhanced Safety of Vehicles, Seoul, Korea, 27-30 May 2013; US National Highway Traffic Safety Administration: Washington DC, USA, 2013.

81. Zhao, Y.; Ito, D.; Mizuno, K. AEB effectiveness evaluation based on car-to-cyclist accident reconstructions using video of drive recorder. Traffic Inj. Prev. 2019, 20, 100-106. [CrossRef] [PubMed] 
82. Salvati, L.; d'Amore, M.; Fiorentino, A.; Pellegrino, A.; Sena, P.; Villecco, F. Development and Testing of a Methodology for the Assessment of Acceptability of LKA Systems. Machines 2020, 8, 47. [CrossRef]

83. Queensland Government. Queensland Road Crash Database Manual; Office of Economic and Statistical Research: Brisbane City, QLD, Australia, 2009; p. 179. 